\title{
THE RADIO DIRECTION FINDER AND ITS APPLICA- TION TO NAVIGATION
}

\author{
By Frederick A. Kolster and Francis W. Dunmore
}

\section{ABSTRACT}

The radio direction finder is a simple instrument by means of which the direction of a radio transmitting station may be determined.

A practical form of direction finder has been developed by the Bureau of Standards, in cooperation with the Bureau of Lighthouses, for use on shipboard, and tests have proved it to be a very useful nautical instrument.

Sound and visual signaling devices have been used at light stations for many years, but during fog, when they are most needed, they fail to give reliable information. The radio direction finder is not affected by fog, and has the further advantage that it will operate over much greater distances.

This paper deals briefly with the principles of the operation of the direction finder, but is primarily concerned with practical development, which has made possible a device sufficiently simple and accurate for use as an aid to navigation, and with practical applications which have been made.

The system described includes the use of the radio direction finder on shipboard in connection with automatically operated radio transmitting apparatus installed at light stations. The paper describes in detail a direction finding system of this type, including radio transmitting apparatus which is in operation on light stations at the entrance to New York harbor and the direction finder installed on shipboard.

As a result of extensive tests, which are described, this method of installing the direction finder on shipboard has been found to have numerous advantages over another system of direction finding, in which each ship transmits radio signals to a number of direction finders located on shore.

The paper points out the importance of establishing as soon as possible radio transmitting stations at the other important light stations on the Atlantic and Pacific coasts and the installation of radio compass equipment on shipboard.

\section{CONTENTS}

II. The radio direction finder $\ldots \ldots \ldots \ldots \ldots \ldots \ldots \ldots \ldots \ldots \ldots \ldots \ldots \ldots \ldots$

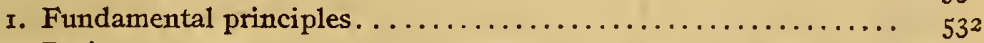

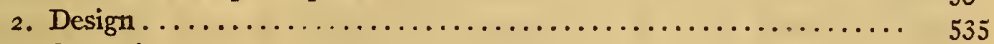

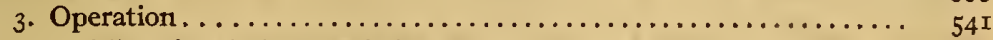

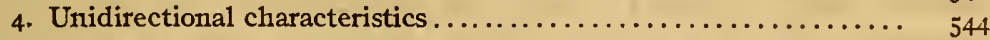

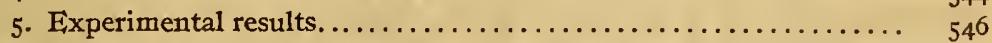

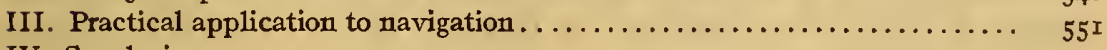

IV. Conclusion . . . . . . . . . . . . . . . . . . . . .

\section{INTRODUCTION}

Sound and visual signaling devices have been employed for many years as aids to navigation. Lighthouses and lightships, with their characteristic light flashes and sound signals, are estab- 
lished and maintained along the coasts and at harbor entrances in order that shipping may be carried on with maximum safety.

Unfortunately, however, during fog or thick weather, when the greatest need for these aids to navigation exists, they fail to serve their purpose adequately. Light does not penetrate fog, and it is well known that sound signals are extremely unreliable and can not be depended upon to indicate direction or distance. Furthermore, even under favorable conditions, the most modern devices for visual or sound signaling are limited to comparatively short distances.

The utilization of electric waves such as are employed in radio communication for fog-signaling purposes has been suggested from time to time, and although early experiments have been made both in this country and abroad for the purpose of determining the practicability of fog signaling by radio no serious attempt has been made to encourage the adoption of the scheme until recently.

In May, I9I3, one of the authors of this paper, acting as a representative of the Department of Commerce on the Interdepartmental Radio Committee on Safety at Sea, strongly advocated that serious consideration be given to the possibilities of radio signaling as an aid to navigation and that the matter be brought before the International Conference on Safety at Sea, which was held in London during that year.

It is well known that electric waves penetrate fog and can be transmitted over much greater distances than light or sound waves. Any lighthouse equipped with a suitable radio transmitting equipment, therefore, becomes an effective radio fogsignaling station whose characteristic signals are readily received by all ships within range irrespective of weather conditions.

Since 1913 the radio laboratory of the Bureau of Standards has given a great deal of attention to the practical development of methods and devices for radio fog signaling and particularly to the development of a suitable instrument for use on shipboard by means of which the direction or bearing of the signaling station may be determined.

It is the purpose of this paper to describe the radio fog-signaling system and especially the direction-finding instrument or radio compass, as it is sometimes called, and to give the principles upon which its operation is based as well as the results obtained in practical use. Under normal conditions this publication would have been released several years ago, but because of the important 
military value of the direction finder, so effectively demonstrated during the war, the Navy Department, in I9I 5, requested that publication as well as civil application be delayed. During the war many naval vessels were equipped with the radio direction finder.

More recently the Navy Department has established an extensive system of direction-finder stations on shore, the purpose of which is to furnish to ships, upon request, radio bearings taken by two or more such stations. In the Navy system the ship whose position is to be determined becomes the signaling station from which radio bearings are taken at two or more direction-finder stations located on shore. The bearings thus obtained are then communicated to the ship by radio.

The system advocated and developed by the Bureaul of Standards in cooperation with the Bureau of Lighthouses is the reverse of the Navy system. Lighthouses and light vessels whose location on sailing charts are accurately shown are equipped with radio fogsignaling apparatus, which automatically transmit their respective characteristic signals during fog or at such times as may be necessary. The direction finder is then required to be installed on shipboard, where it may be operated directly by the navigating officer, who can take bearings at any time and as often as he desires on any one or more of the radio fog-signaling stations established and operated by the Bureau of Lighthouses.

Extensive tests have been conducted with the view of determining the practicability of the Bureau of Standards system. So successful have been the results that it is predicted that within a short time every important lighthouse and light vessel will become a radio fog-signaling station, and the radio direction finder will become as much a part of a ship's equipment as the magnetic compass. An extremely effective aid to navigation will thus be provided which, if universally adopted, will result in more adequately protecting life and property at sea.

The cost of a direction finder for shipboard installation is so small as compared with the benefits which may be derived therefrom, perhaps in a single instance, where life, property, or even time may be saved, that it can not enter into consideration. Likewise the cost to the Government of establishing radiosignaling stations at lighthouses and on light vessels is small as compared to their value as substantial aids to navigation, particularly since no additional personnel is required in their operation and maintenance. 
International recognition of the future importance of radio fog-signaling has been recorded in the report of the Interallied Radio Commission which met in Paris in I9rg and later in the report of the Universal Electrical Communications Union which met in Washington in 1920 .

The following recommendations concerning the operation of radio fog-signaling or radio-beacon stations, based upon practical experience obtained during actual tests, were submitted to the Communications Union by the Bureau of Standards for international consideration.

\section{Service of Radio Beacon Stations}

Each administration which shall install radio beacons shall observe the following conditions:

Radio beacons adopted for the needs of navigation shall be divided into three classes:

I. Short-range radio beacons.

2. Long-range radio beacons.

3. Radio beacons on shipboard.

The transmitting wave length for these three classes of beacons shall be rooo meters, spark or interrupted continuous waves.

Short-range shore beacons shall be limited in power such that accurate radio bearings can be taken at a distance of 30 miles. During fog or at such times as may be determined by the administration, these beacons shall transmit characteristic signals whose form, frequency, and tone shall be fixed by the administration.

Long-range shore beacons shall be limited in power such that accurate radio bearings can be taken at a distance of 300 miles. These long-range beacons shall be limited in number and shall operate at infrequent intervals during fog or at such times as may be determined by the administration. The form, frequency, and tone of the characteristic signal transmitted by these stations shall be determined by the administration.

Radio beacons on shipboard shall be limited in power such that accurate radio bearings may be taken at a distance of to miles. During fog or thick weather, shipboard beacons shall transmit characteristic signals at frequent intervals commencing with the call signal repeated for 30 seconds and terminating with the indication of the ship's course and speed.

Radio beacons on permanently moored vessels, such as light ships, shall be considered as shore beacons.

BUREAU OF STANDARdS Radio LABoratory.

Washington, D. C., October I5, 1920.

\section{THE RADIO DIRECTION FINDER}

\section{FUNDAMENTAL PRINCIPLES}

The fundamental radio circuit is made up of inductance and capacity. These elements appear in various forms, and in the ideal circuit, as shown diagrammatically in Fig. I, the inductance 
is entirely concentrated or lumped in the coil $L$, and the capacity is likewise concentrated or lumped in the condenser $C$.

Power may be supplied to such a circuit either by applying a resonant voltage across the condenser $C$ or by inducing a resonant voltage in the coil $L$, or by action of both in proper phase relation.

In the ordinary antenna circuit, as used in present-day radio communication, we find, generally speaking, that the inductance is substantially concentrated in the form of a coil $L$, and that the capacity is formed by a conductor or group of conductors elevated above the ground, the elevated conductors forming one plate of the condenser and the ground or counterpoise forming the other plate, as shown in Fig. 2.

It may be said, therefore, that energy is received in the ordinary radio antenna system by virtue of the fact that its capac-

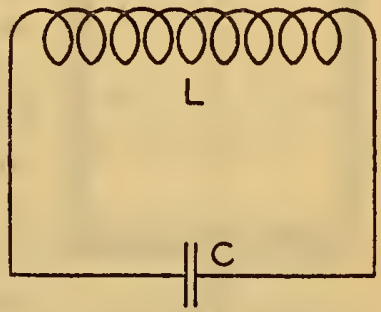

FIG. I.-Simple radio circuit ity is exposed to the incoming electromagnetic wave or, in other words, that energy enters the system by way of its capacity, thereafter to be transferred to its inductance. The electrical capacity of an antenna as well as the potential impressed upon it by the incoming electromagnetic wave depends largely upon its physical dimensions, generally the size and height of its elevated area and in special types of antennas, mainly upon the length of the antenna wires.

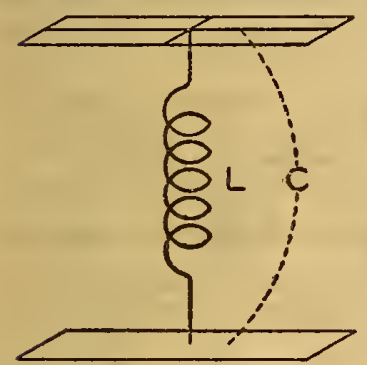

Fig. 2.-Antenna consisting of elevated conductors (condenser type)

Referring now to Fig. 3, we have what may be considered as the reverse of the antenna system shown in Fig. 2. In this case energy is received in the system by virtue of the fact that its inductance $L$ is exposed to the incoming electromagnetic wave or, in other words, energy enters the system by way of its inductance, thereafter to be transferred to its capacity.

The inductance of coil $L$ depends upon the number of turns, the area inclosed, and the spacing of the turns. The current in the receiving circuit depends largely upon these factors as well as the resistance of the circuit. For given physical dimensions, however, any value of inductance may be obtained by winding the proper number of turns in the coil $L$, so that the electrical dimensions of the coil system are not so dependent upon its physi- 
cal dimensions as is the ordinary antenna system. As a matter of fact, a coil system of very small dimensions as compared with an antenna may be used for the reception of radio signals.

Although the coil-receiving system is superior in many respects to the antenna system, its chief advantage lies in its directive properties. If the coil $L$ in Fig. 3, for example, is rotated about its vertical axis $a b$, the received signal intensity from any given

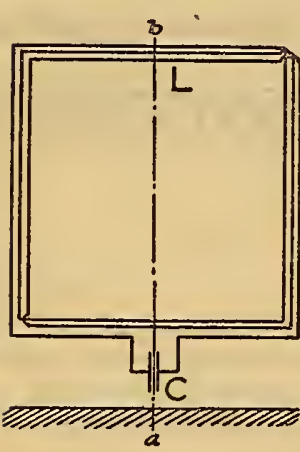

Fig. 3.-Antenna consisting of closed coil (inductance type) source of transmission will vary approximately in accordance with the diagram shown in Fig. 4.

Maximum signal intensity $O P$ or $O M$ is obtained when the plane of the coil $L$ lies in the direction of the source of transmission $A$ or $B$. If the source is in the direction $C$ or $D$, or exactly normal or at right angles to the plane of the coil $L$, then the signal intensity is zero. In all other directions the intensity varies in accordance with the figure-of-eight characteristics in Fig. 4. For example, in directions $O E$ or $O F, O G$ or $O H$, the distances $O N$ or $O Q$ respectively represent the relative signal intensities as compared with the maximum $O M$ or $O P$.

It is immediately apparent, therefore, that if the coil $L$ in Fig. 3 is of sufficiently small dimensions to permit rotation about its vertical axis, signals transmitted from any given source will be received with gradually varying degrees, of intensity until the coil becomes normal or at right angles to the direction in which the transmitting source lies, at which time the signal intensity becomes zero. This position of silence is critical, and therefore may be used to indicate, with great accuracy, the line of direction of the source.

It is upon these simple principles that the direction finder as developed

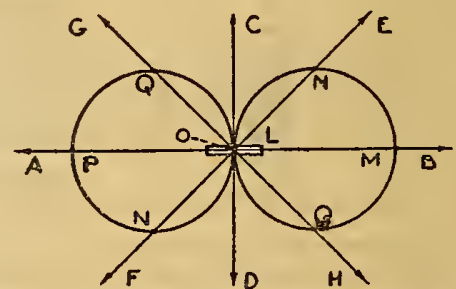

FIG. 4.-Theoretical directional characteristic of closed coil antenna at the Bureau of Standards is based. The theory of its design and operation presents a number of interesting problems, however, and it is not until these problems are thoroughly understood that the ideal conditions for accurate direction finding can be realized. 
In the matter of design it is of importance to determine under given practical conditions the number of turns and the spacing of the turns which will give maximum received signal intensity for the wave length or range of wave lengths to be received.

In the matter of operation it is of importance to obtain as nearly as possible the ideal figure-of-eight characteristic with its critical or sharply defined position of zero signal intensity. The operating circuit adjustments and the method of reading bearings must be simple and rapid.

\section{DESIGN}

The main electrical circuit of the direction finder or coil receiving system is nothing more nor less than a simple radio circuit containing inductance, resistance, and capacity, and may be treated as such in every respect. No new theory enters into its electrical behavior, and in determining best circuit conditions it is only necessary to define the practical requirements.

Without going into the theory in great detail, we shall consider for the purpose of illustration two cases involving different initial requirements. In both cases the dimensions of the coil, the number of turns, and the spacing between tirns are

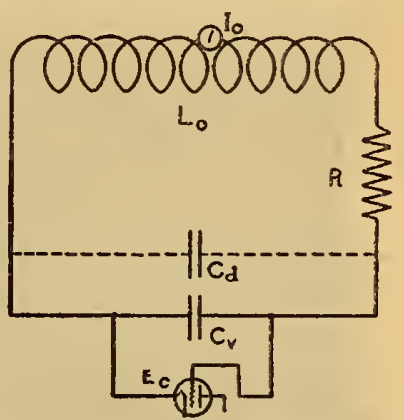

FIG. 5.-Coil antenna circuit showing distributed capacity and resistance fixed. It will then be the purpose in one case to determine the wave length or range of wave lengths which will give maximum received current in the coil and in the other case to determine the wave length or range of wave lengths which will give maximum potential difference across the tuning condenser. A constant source of undamped or continuous wave transmission will be assumed.

CASE I.-To determine the wave length which will produce maximum current at center of coil $L_{0}$. (See Fig. 5.)

$L_{0}=20$ turns, 4 feet by 4 feet, higl-frequency cable 48 strands No. 38 wire. One-half inch separation between turns.

$R=$ resistance of circuit measured at center of coil.

$C_{d}=$ effective distributed capacity of coil $L_{0}=39$ micromicrofarads.

$C_{v}=$ variable tuning condenser. 
For given undamped wave transmission, the received current in the coil $L_{0}$ may be expressed in terms of the circuit constants.

where

$$
I=\text { constant } \times \frac{A N}{R \sqrt{\bar{L}_{0} C_{0}}}=\text { constant } \times \frac{A N}{R \lambda}
$$

$A=$ area of coil.

$N=$ number of turns.

$R=$ resistance.

$L_{0}=$ inductance of coil.

$C_{0}=$ total capacity $=C_{d}+C_{v}$.

$\lambda=$ wave length in meters.

Since in the case in question the area and number of turns are fixed we need only to consider the variation of current with

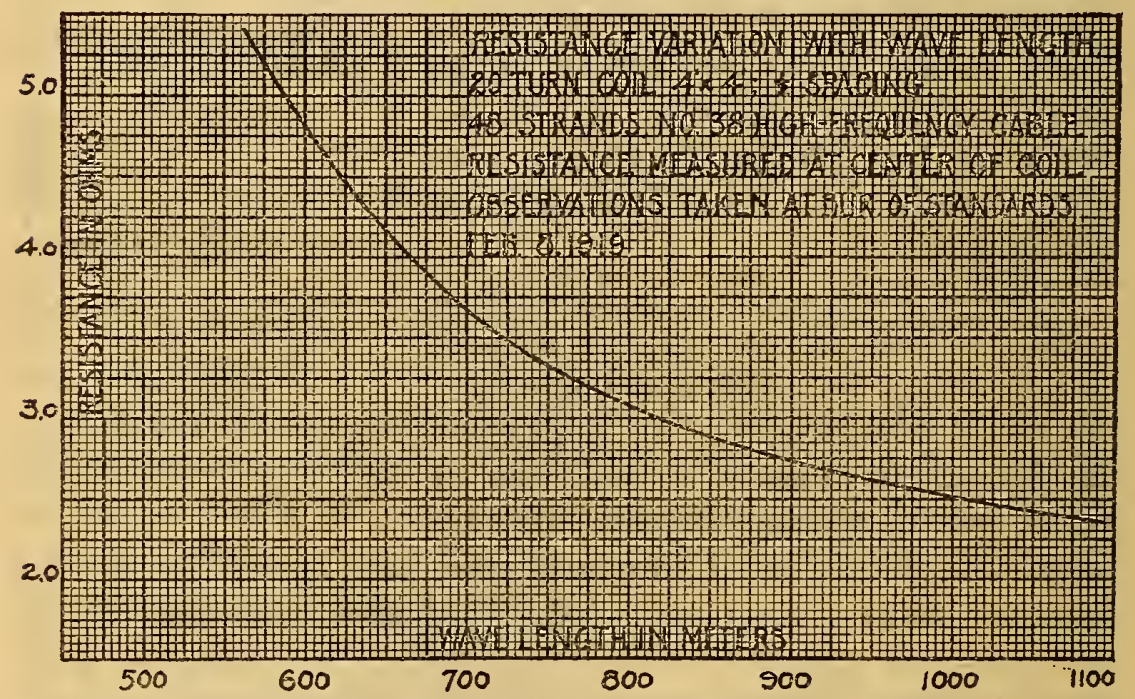

FIG. 6.-Resistance variation with wave length of a 20-turn coil

resistance and wave length. This involves the measurement of the high-frequency resistance of the coil, and if the current were uniformly distributed throughout the coil this resistance could be measured at any point in the coil, but due to the inherent distributed capacity of the coil which, although very small as compared to the tuning condenser capacity at the longer wave lengths when the tuning condenser is large, has appreciable effect at the shorter wave lengths when the tuning capacity is small, the resistance should be measured with reference to the part of the coil in which the current is to be determined. In this case the current at the center of the coil will be determined and therefore the resistance measurements are made at the center. 
The resistance variation with wave length thus measured is shown in Fig. 6 and the calculated data for the current variation, proportional to $\frac{1}{\lambda R}$, is given in Table $\mathrm{I}$.

TABLE 1.-Data for Case 1

\begin{tabular}{|c|c|c|c|}
\hline$\stackrel{\lambda}{\lambda}$ & $\mathbf{C}_{0}=\underset{(\mu \mu f)}{\mathbf{C}_{d} \pm \mathbf{C}_{v}}$ & $\underset{\text { (ohms) }}{R}$ & $\frac{10^{6}}{\lambda R}$ \\
\hline $550 \ldots \ldots$ & 89 & 5.70 & 319 \\
\hline 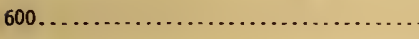 & 105 & 4.80 & 347 \\
\hline $700 \ldots \ldots \ldots \ldots \ldots \ldots \ldots \ldots \ldots \ldots \ldots \ldots \ldots \ldots \ldots$ & 145 & 3.75 & 380 \\
\hline $800 \ldots \ldots \ldots \ldots \ldots \ldots \ldots \ldots \ldots \ldots \ldots \ldots \ldots \ldots \ldots$ & 189 & 3.13 & 399 \\
\hline $900 \ldots \ldots \ldots \ldots \ldots \ldots \ldots$ & 240 & 2.75 & 404 \\
\hline 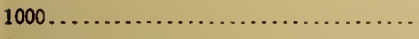 & 295 & 2.50 & 400 \\
\hline $1100 \ldots \ldots \ldots \ldots \ldots \ldots$ & 355 & 2.40 & 378 \\
\hline $1200 \ldots \ldots \ldots \ldots \ldots$ & 423 & 2.35 & 354 \\
\hline
\end{tabular}

The current variation is shown in Fig. 7 , and it will be seen that maximum current is obtained at a wave length of 900 meters.

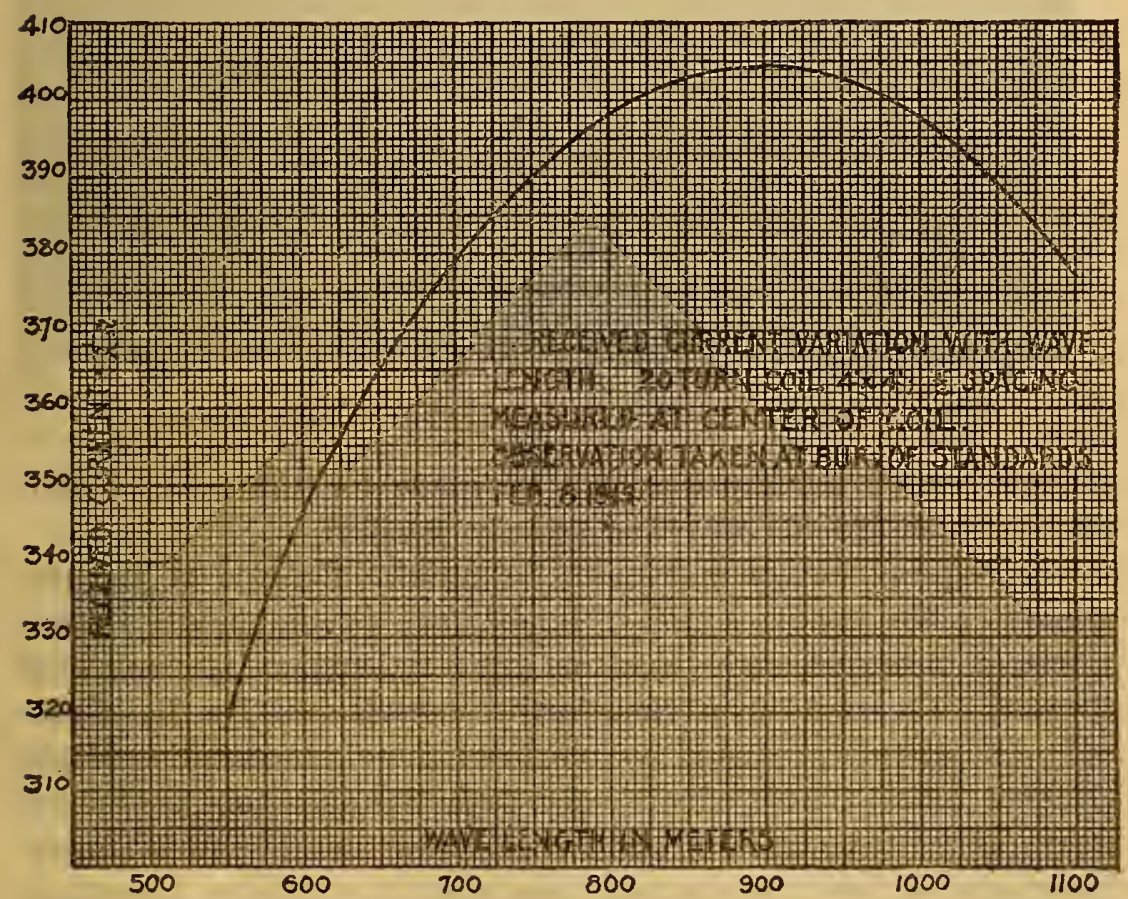

FiG. 7.-Received current variation with wave length

This case serves as an example of a practical case where the detector circuit is associated inductively with the coil $L_{0}$ and preferably at the center of the coil, and if it be assumed that no 
appreciable increase in resistance is introduced because of the loosely coupled detector circuit, then the coil system above described would function with maximum efficiency when receiving a wave length of 900 meters.

CASE 2.-Maximum potential at terminals of condenser.

Due to the distributed capacity of the coil and the consequent nonuniform distribution of current through the coil at the shorter wave lengths this case presents somewhat more difficulty in its treatment than case I. However, the data given in what follows will serve sufficiently well for the purpose intended even

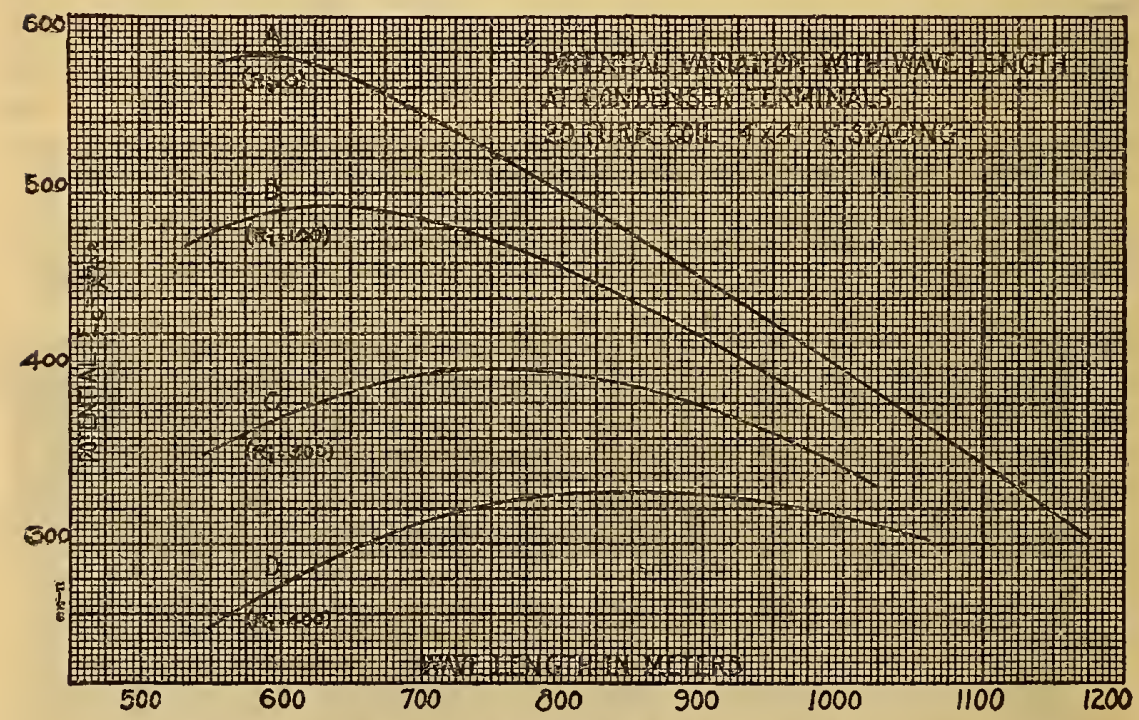

FIG. 8.-Potential variation with wave length at condenser terminals

though certain assumptions will be made for the sake of simplicity which are not otherwise strictly justified.

The requirement of maximum potential difference at the terminals of the condenser is of importance in the practical case where a three-electrode electron tube or audion is connected thereto. The problem is then further complicated by the effects upon the circuit produced by virtue of the characteristics of the electron tube. These effects vary with the operating characteristics of the tube circuits and hence unless one has an accurate knowledge of how the electron tube with its auxiliary apparatus will modify the coil system under all conditions, no accurate nor definite determination of the conditions for maximum potential difference can be made. 
Let us take by way of example the case wherein it is desired to determine the variation with wave length of the voltage at the terminals of the condenser in the coil system described in case $I$. The assumption will be made that the distributed capacity of the coil $L_{0}$, Fig. 5 , can be represented as a perfect condenser $C_{d}$ in parallel with the perfect tuning condenser $C_{v}$, giving a total capacity $C_{0}=C_{d}+C_{v}$. Furthermore, it will be assumed that the current variation with wave length in the combined condenser paths will be as determined in case I and shown by the curve in Fig. 7.

Then if $I=$ constant $\times \frac{A N}{R \lambda}$

then $E_{c}=\frac{I}{C_{0} \omega}=$ constant $\times \frac{A N}{R C_{0}}=$ constant $\times \frac{A N L}{R \lambda^{2}}$

For the case in question where $A, N$, and $L$ are given and remain constant,

$$
\mathrm{E}_{c}=\text { constant } \times \frac{1}{R \lambda^{2}}
$$

TABLE 2.-Data for Case 2

\begin{tabular}{|c|c|c|c|}
\hline 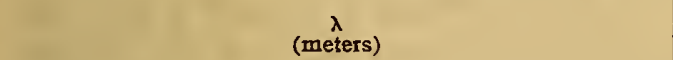 & $\mathrm{C}_{0}=\mathrm{C}_{d \mu f}+\mathrm{C}_{\boldsymbol{j}}$ & (ohms) & $\frac{109}{R \lambda^{2}}$ \\
\hline $550 \ldots . .$. & 89 & 5.70 & 580 \\
\hline $600 \ldots \ldots . . .$. & 105 & 4.80 & 578 \\
\hline $700 \ldots \ldots . . .$. & 145 & 3.75 & 54 \\
\hline $800 \ldots \ldots . . .$. & 189 & 3.13 & 498 \\
\hline 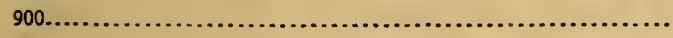 & 240 & 2.75 & 448 \\
\hline 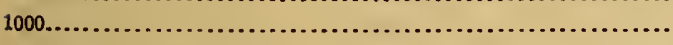 & 295 & 2.50 & 40 \\
\hline 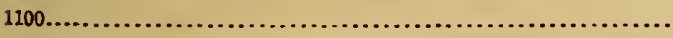 & 355 & 2.40 & 34 \\
\hline $1200 \ldots . . .$. & 423 & 2.35 & $29:$ \\
\hline
\end{tabular}

This variation of voltage with wave length is given by the curve $A$ in Fig. 8, which shows that the maximum potential is obtained across the capacity of the coil system when receiving a wave length of about 550 meters.

In the practical case this condition would be true if the detecting apparatus connected to the terminals of the condenser were purely potentially operated and absorbed no energy from the coil system. The above example, therefore, serves to illustrate the practical conditions which would exist in the case where a vacuum tube circuit having zero input resistance is connected to the condenser $C_{v}$. 
The potential variations with wave length for cases where the input resistance of the electron-tube circuit has an appreciable positive value, which it will be assumed remains constant over the wave-length range, are shown in Fig. 8 by curves $B, C$, and $D$.

The data from which these curves were drawn were obtained by considering the input circuit of the electron tube as equivalent to a capacity $C_{i}$ in series with a resistance $R_{i}$. The complete coil system may then be shown as in Fig. 9.

Having obtained the coil circuit resistance $R$ for various wave lengths by measurement as in case $I$, the effective increase in circuit resistance $\Delta R$ due to the input resistance $R_{i}$ may be calculated from the formula:

$$
\Delta R=R_{i} \times\left(\frac{C_{i}}{C_{0}}\right)^{2}
$$

where $C_{0}$ is the total capacity $C_{d}+C_{v}+C_{i}$.

Here again the assumption is made that the capacities $C_{d}$ and $C_{v}$ are in the nature of perfect condensers and that currents in the

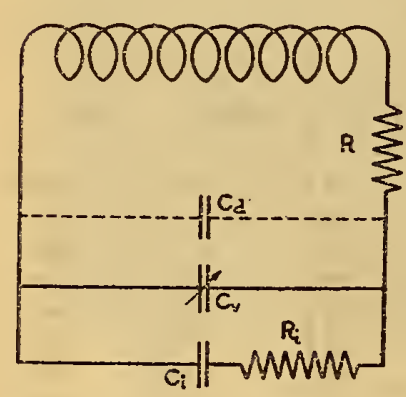

Fig. 9.--Equivalent coil system three condenser branches are substantially in phase.

In Fig. 8 , curves $B, C$, and $D$ give the variation with wave length of the voltage across a condenser $C_{0}=C_{d}+C_{v}+C_{i}$, when the coil circuit resistance is $R+\Delta R, R$ being given by the curve in Fig. 6 and $\Delta R$ being calculated for $R_{i}=$ roo ohms for case $B, 300$ ohms for case $C$, and 600 ohms for case $D$.

The value of $R_{i}$ in practice depends, of course, upon the type of electron-tube circuits employed and the operating adjustments used for each wave length. In fact, when the inductance in the plate circuit becomes larger than a certain value a reduction of circuit resistance is effected; that is, $\Delta R$ becomes negative.

It is seen, therefore, that the design of a coil system in which the electron-tube apparatus is to be directly connected across the tuning condenser is thoroughly dependent upon the characteristics and adjustments of the electron-tube circuits. Generally speaking, however, best receiving efficiency for a given coil is obtained at the shorter wave lengths where small condenser capacities are required. For example, in the case of the zo-turn 
coil herein described, for which let us take curve $A$ in Fig. 8 as being a fair representation of a practical case, it is seen that a received wave length of between 500 and 600 meters will give maximum effect. The natural wave length of the coil as determined by its inductance and distributed capacity is approximately 400 meters.

\section{OPERATION}

Naturally the operation of the coil system as a direction finder depends upon its design, and although it is desirable to obtain as nearly as possible the conditions for maximum receiving efficiency, good direction-finding characteristics are of first importance. Best receiving conditions are often obtained at wave lengths close to the natural wave length of the coil when using the voltage operated detector system, but under these conditions good direction-finding qualities are not generally obtained.

An important factor which up to this point has not been considered enters into the operation of the coil system, particularly in its use as a direction finder. This has to do with the effects produced in the coil system by virtue of the fact that the coil structure has an appreciable capacity to earth. Furthermore, the entire coil system, including the detector circuits, connected thereto, is electrically unsymmetrical with respect to earth. This results

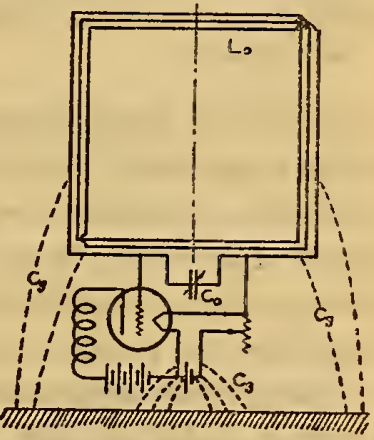

Fig. Io.-Coil antenna circuit, showing asymmetry of distributed capacity to earth in a distortion of the ideal figure-of-eight signal intensity characteristic obtained by rotation of the coil about its vertical axis. The critical position of zero signal intensity no longer exists and the directive qualities of the coil system are obscured.

An examination of Fig. ro will show that the electron-tube circuit connected to the condenser $C_{0}$ will be operated upon by the potential across the condenser as produced by the current received in the coil $L_{0}$ by the direct action upon the coil of the incoming electromagnetic wave. It will also be operated upon to a lesser extent by the voltage applied to the electron tube due to direct action upon it of the incoming wave through the earth capacities $C_{\sigma}$. Furthermore, because of the electrically unsymmetrical relation of the coil system with respect to earth, an appreciable current will be set up in the coil circuit by the incoming wave acting through the earth capacities $C_{\sigma}$. The potential produced 
by this current across the condenser $C_{0}$ will likewise operate upon the electron tube.

The ideal figure-of-eight signal intensity characteristic is therefore distorted by these additional effects, the degree of distortion depending upon their relative magnitudes. In practice it often happens that the signal intensity produced by direct action through the earth capacity is sufficient to destroy the critical zero signal

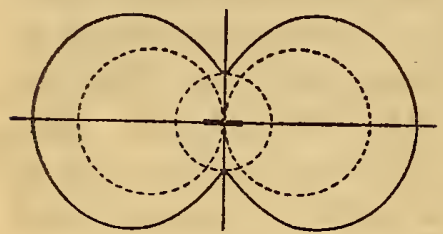

FIG. II.-Coil characteristic, shoreing effect of direct action through earth capacity characteristic of the coil when its plane is at right angles to the incoming wave front. This effect is illustrated by Fig. II, in which the dotted tangential circles or figure-of-eight represents the ideal variations of signal intensity for various positions of the coil with respect to a given source, and the small circle represents the variation of signal intensity produced by direct action through the earth capacities. It is seen that this signal is independent of coil position. Furthermore, it is produced by a voltage which is in quadrature with the condenser voltage which produces the figureof-eight signal variation. The characteristic shown in full line is therefore the resultant effect.

The further effect produced by the voltage operating upon the electron tube as the result of a current set up in the coil by the action of the incoming wave through the earth capacity is shown in Fig. 12.

In this case the constant signal intensity represented by the small circle is produced by a voltage which is either in phase or $180^{\circ}$

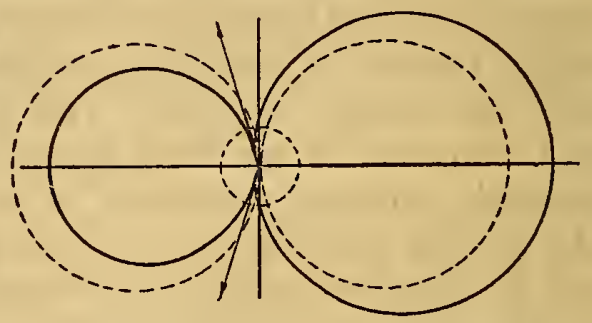

FIG. I2.-Coil characteristic, showing effect of current set up in coil by capacity to earth

out of phase with the condenser potential giving the figure-ofeight signal characteristic, depending upon the relative position of the coil with respect to the incoming wave. The resultant characteristic is given by the full-line figure. It will be noted that the positions of zero signal intensity are no longer at right angles to the plane of the coil, nor do they coincide with the axis of the coil as in the ideal case. This is a very common occur- 
rence in practice which leads to considerable annoyance if not properly taken care of.

Finally, we have in Fig. I 3 a representation of the signal variation characteristic which results when both effects described with reference to Figs. I I and I 2 are present.

For accurate direction finding such conditions can not be tolerated, and means must therefore be applied to minimize or entirely eliminate these undesirable effects.

First of all, it is essential to avoid using the direction finder at or near the natural wave length of the coil where the abovedescribed effects are likely to be magnified. At the same time receiving efficiency must not be sacrificed to too great an extent.

The complete solution of the problem depends upon obtaining exact electrical symmetry of the entire coil system, including the auxiliary electron-tube apparatus, with respect to earth.

The capacity with respect to earth of a direction-finder coil depends upon its physical dimensions and its height above earth. For a coil of given area and placed at a given height above earth, this capacity will vary with the spacing

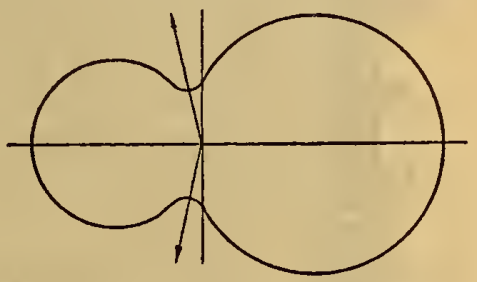

of the turns. If the windings of the coil are widely separated, the axial length of the coil is great, and its capacity to earth is increased.

In Fig. I4 the variation of capacity to earth with spacing of turns for a coil 5 by 5 feet wound with 12 turns is given for two cases. Curve $\mathrm{I}$ gives the value of earth capacity for various spacings when the coil was 2 feet above earth and curve 2 when 5 feet above earth.

In determining the best spacing of turns in the matter of design there are, therefore, two factors to be considered. The distributed capacity of the coil and hence its natural wave length must be reduced by separating the windings. However, this should not be carried so far as to make the axial length and hence the capacity to earth too great.

As stated above, for direction-finding purposes the coil system should be electrically symmetrical with respect to earth. This condition can be brought about by proper adjustment of the condensers $C_{1}$ and $C_{2}$ in Fig. 15. Furthermore, the condensers $69405^{\circ}-22-2$ 
$C_{0}, C_{1}$, and $C_{2}$, together with all other auxiliary apparatus, should be shielded as shown by $S$.

The electrical symmetry can further be improved by avoiding direct connection of the electron tube to the circuit as shown in Fig. I6. In this case the electron tube is connected to the second-

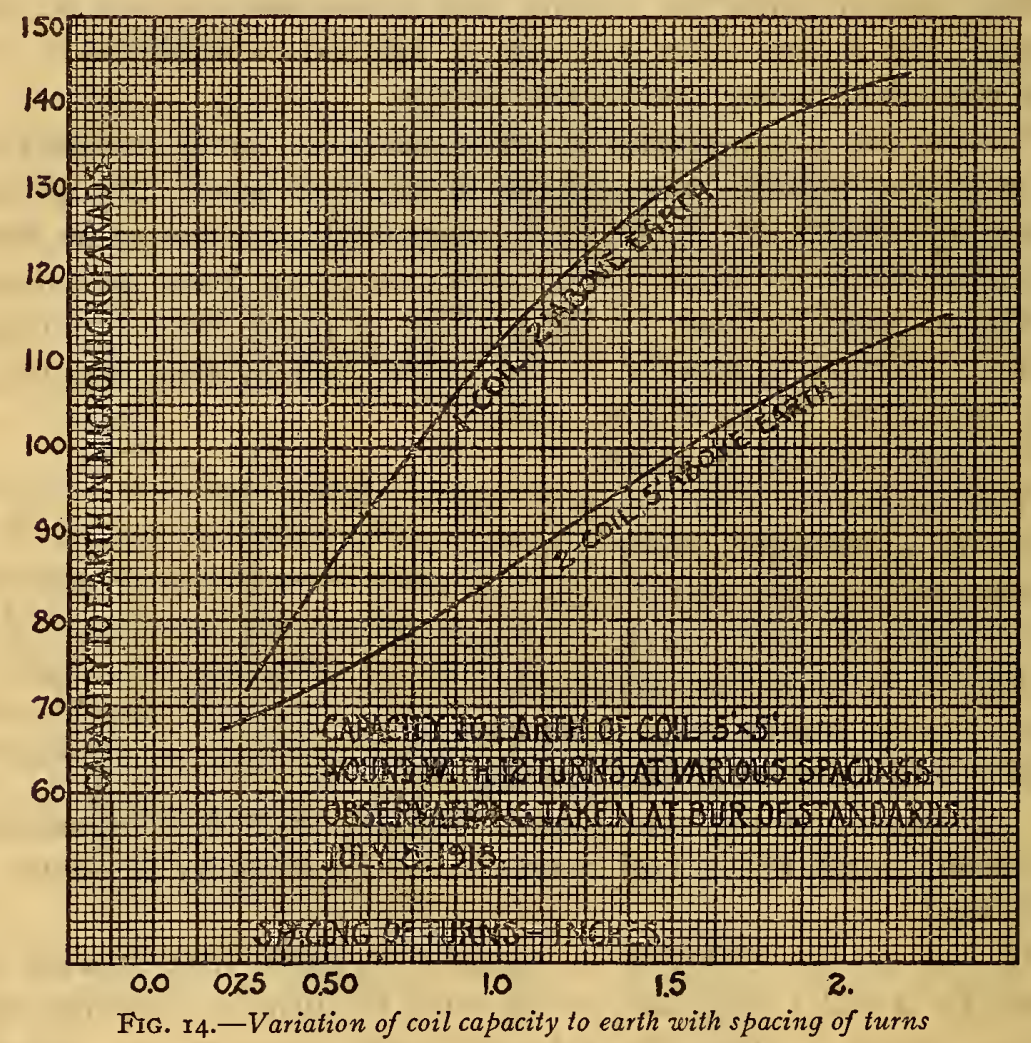

ary winding of a suitable transformer, the primary of which is connected to the condenser $C_{0}$.

The arrangement shown in Fig. I 7 , wherein a double-grid and double-plate electron tube is used, affords excellent symmetry.

In any case it is of the greatest importance that the electron-tube system which in practice usually consists of a detector tube with one or more stages of radio and audio amplification shall be operated upon only by the direct action of the incoming wave upon the coil $L_{0}$.

\section{UNIDIRECTIONAI CHARACTERISTICS}

The rotatable coil system with its critical position of zero signal intensity is a direction finder to the extent that the line of direction in which a radio transmitting source lies can be accurately 
determined. The sense of direction, however, is not indicated; that is to say, it is known that the source lies on the axis of the coil but it is not known whether it lies to one side or the other of the plane of the coil.

To provide simple means of determining the sense as well as the line of direction is of practical importance, for example, in locating and proceeding to the aid of a ship in distress.

By accentuating and utilizing the effect described in connection with Fig. 12 where the received signal results from the combined effects of the current set up in the coil by direct action of the incoming wave together with that produced indirectly through the earth capacity, a unidirectional characteristic may be obtained

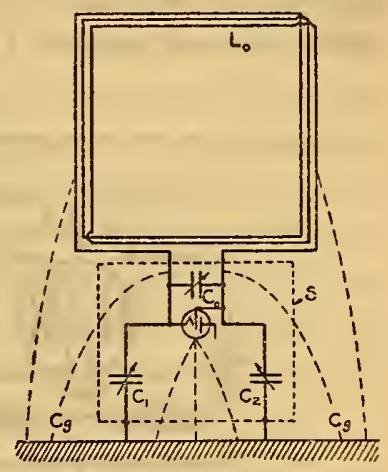

FIG. I5.-Circuit showing method of abtaining sym- metry of coil capacity to earth, using balancing condensers by virtue of which the sense of direction is readily determined.

This can be accomplished by the system shown in Fig. I 8 , in which a tuning inductance $L_{g}$ is inserted in the earth connection between the condensers $C_{1}$ and $C_{2}$. If now, the

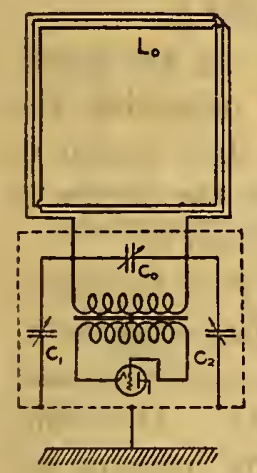

FIG. 16.-Method of obtaining symmetry of coilcapacity to earth, using balancing con. densers and coupling transformer electrical symmetry of the coil system with respect to earth is upset by reducing the capacity $C_{1}$ and increasing the capacity $C_{2}$ or vice versa, a current will be set up in the coil $L_{0}$ by indirect action through the tuned path including $L_{g}$ and $C_{g}$. The signal intensity produced by this current is independent of the relative position of the coil $L_{o}$ with respect to the transmitting source and may be made equal to that produced by direct action upon coil $L_{0}$ when its plane is in the line of direction of the source. Because of the phase relation of the currents set up in coil $L_{0}$ the signal intensities resulting therefrom will be accumulative or differential depending upon whether the source of transmission is at $A$ or at $B$ in Fig. 19. This unidirectional effect may be utilized for the purpose of determining the sense of direction of a transmitting source. For example, if the direction of a source of transmission is found to be in the line $A B$, Fig. 19, the fact that it is at $B$ and not at $A$ is determined by observing the direction indicated by the arrow $S$ attached to the coil $L_{o}$, when maximum signal is obtained. 
Another method of accomplishing the same result without disturbing the electrical symmetry of the coil system with respect to earth is shown in Fig. 20. In this case the indirect action upon the coil circuit $L_{0} C_{0}$ is produced by inductively coupling

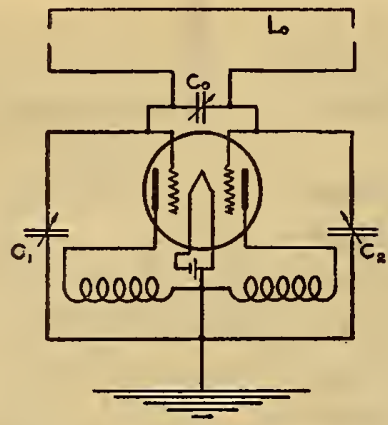

Fig. I7.-Use of double-grid tube to obtain symmetry of coil system

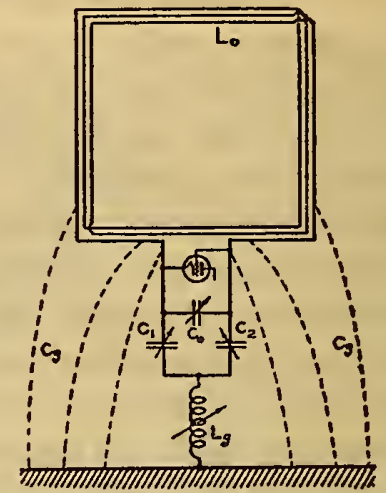

FIG. I8.-Unidirectional coil antenna system, using unbalanced method

the earth circuit $L_{g} C_{g}$ to the coil circuit through the coupling coils $l_{g}$ and $l_{2}$. In order to maintain electrical symmetry the coil $l_{1}$ is used to balance the effect of the similar coil $l_{2}$.

In the system described in connection with Fig. 19, the unidirectional characteristic is controlled entirely by adjusting the condensers $C_{1}$ and $C_{2}$ in opposite sense, while in that shown in

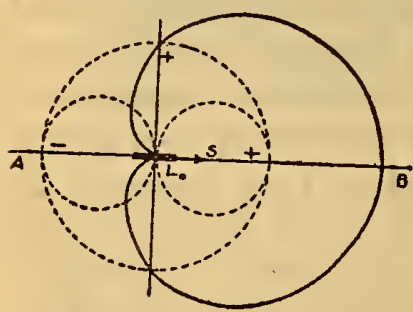

FIG. Iو.-Unidirectional coilcharacteristic

Fig. 20 it is controlled by the degree of coupling between coils $l_{2}$ and $l_{g}$.

The receiving efficiency of the earth circuit $L_{g} C_{g}$ is in some cases not sufficient to produce complete unidirectional effect as shown in Fig. 19. This difficulty can be corrected by utilizing an additional capacity area in combination with the coils $L_{0}$ as shown in Fig. $2 x$ in which the capacity area $A$ is connected to the middle point of the coil $L$, thereby increasing the earth capacity $C_{g}$ and maintaining, when desired, perfect electrical symmetry.

\section{EXPERIMENTAL RESULTS}

A large number of tests have been conducted to determine the accuracy of the coil system herein described when used as a direction finder. For example, in Fig. 22 results of field tests are 
shown wherein the direction of a transmitting source located at the Bureau of Standards was observed by means of a portable direction finder set up at various points in the vicinity of the Bureau.

It will be seen upon examination of Fig. 22 that with the exception of two cases the direction of the source was observed with considerable accuracy. Observations made at the north end of the Sixteenth Street bridge and at the intersection of Ingomar Street and Belt Road gave directions several degrees out. These locations were purposely chosen in order to show the distorting effect upon the wave front of large structures and of

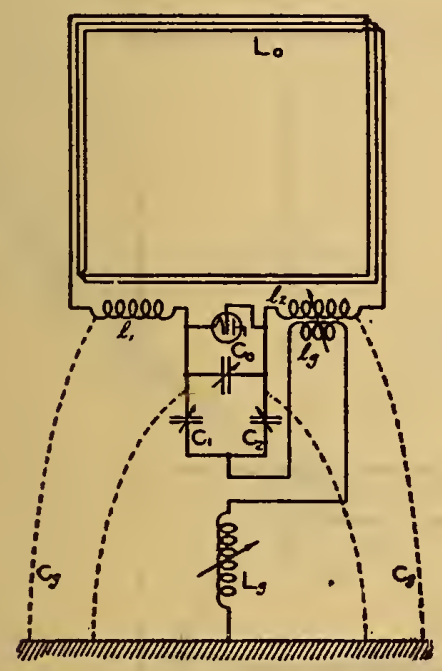

Fic. 20.-Unidirectional coil antenna system, using balanced method and coupling

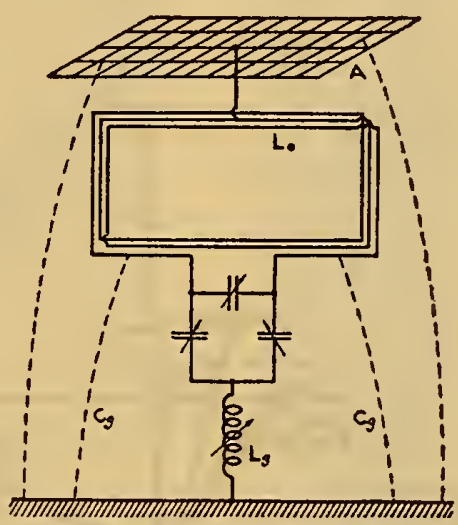

Fig. 21.-Unidirectional coil antenna system, using elevated capacity area

telephone and power lines. In all other cases care was taken in choosing locations free from obstructions, although in several cases the direction finder was set up in rather thickly wooded sections. Trees apparently have little distorting effect.

The portable direction finder used in these tests was designed and constructed at the Bureau of Standards. It has several interesting features and is very convenient for field work. The coil is wound in two sections of five turns each sewed in waterproof canvas. A switch is provided by means of which the fiveturn sections may be connected either in parallel or series. With a tuning condenser, having a maximum capacity of approximately one-thousandth microfarad, a wave-length range of from 300 to 1500 meters is thus readily obtained. 
Several views of the portable direction finder are shown in Figs. 23, 24, and 25. In Fig. 25 the magnetic compass needle and degree scale are shown.

When setting up the direction finder the zero degree mark of the scale is set to coincide with the magnetic north-and-south line and the scale then clamped. The direction of the transmit-

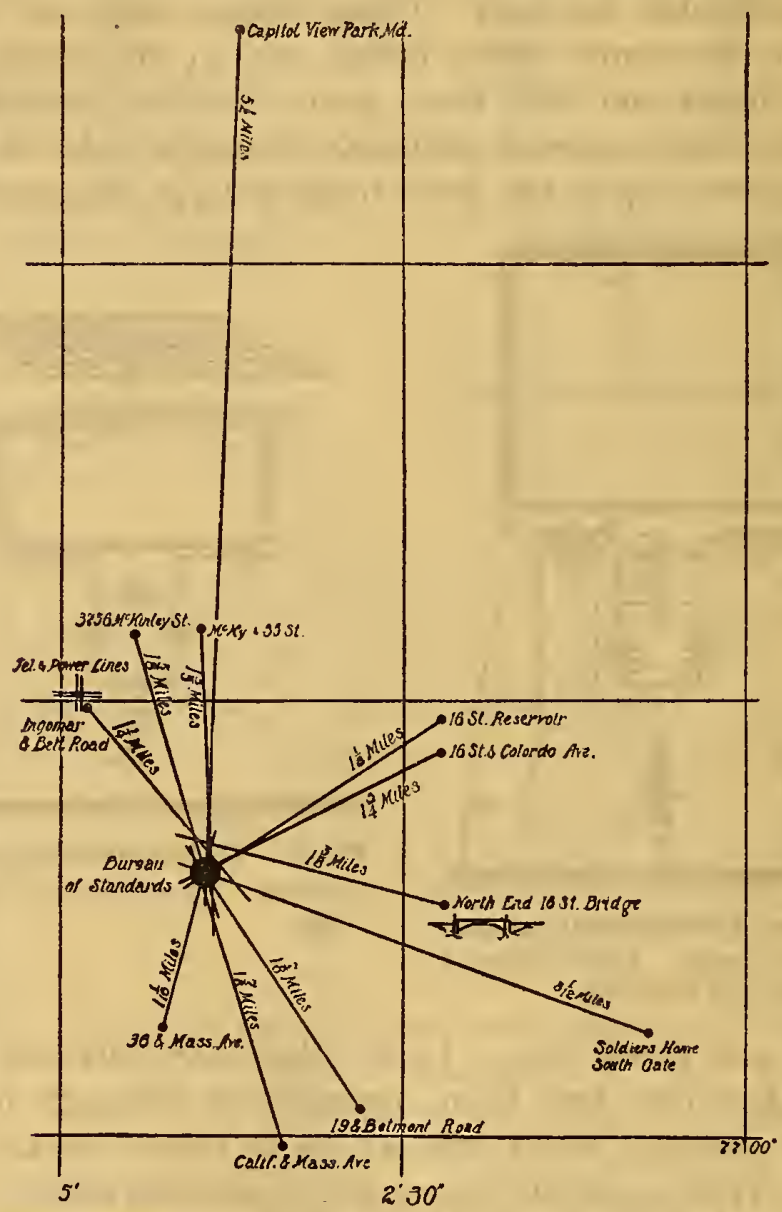

FIG. 22.-Bearings taken on signals from Bureau of Standards with portable direction finder

ting source is then observed by rotating the coil to the position of critical silence at which position the scale reading is noted. The direction of the source is thus given with respect to magnetic north.

Coming back now to the matter of wave distortion caused by the proximity of large metallic structures and other energy-absorbing 


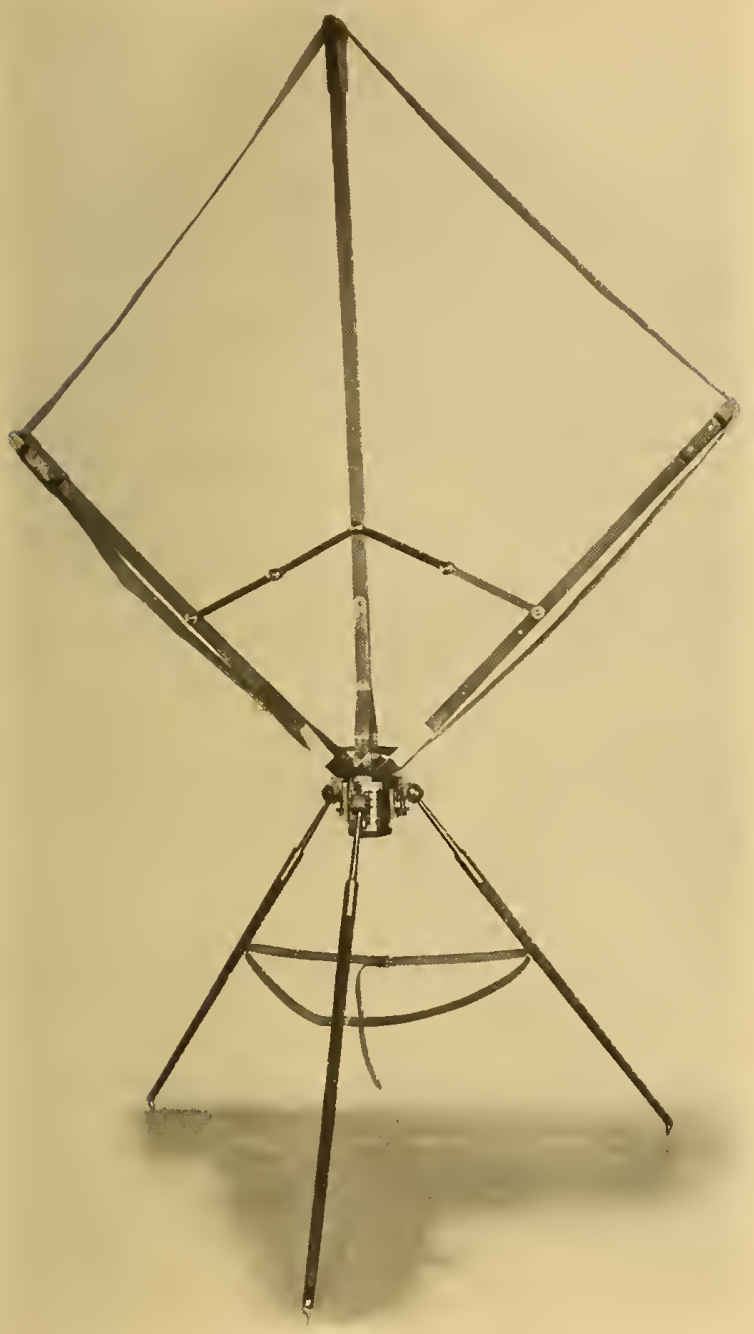

IIG. 23. Collapible type of dirclion finder for ficld use

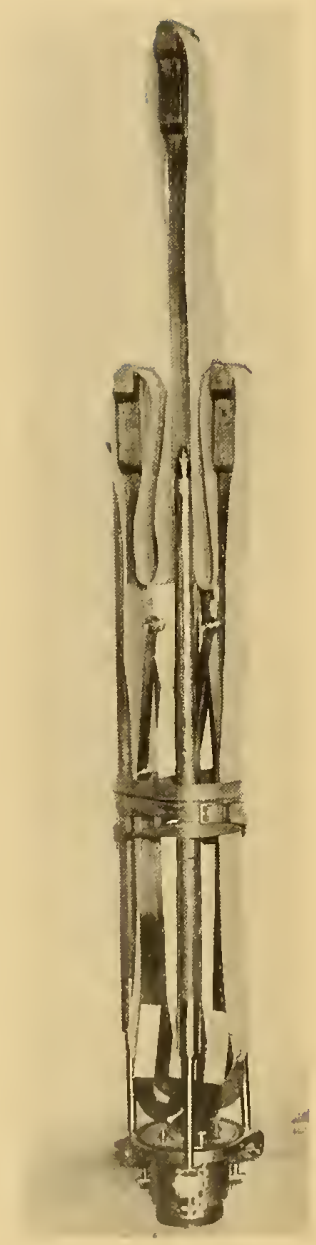

Iirg. 24.-Collapsible type of direction finder ready, for transportation 
Scientific Papers of the Bureau of Standards, Vol. 17

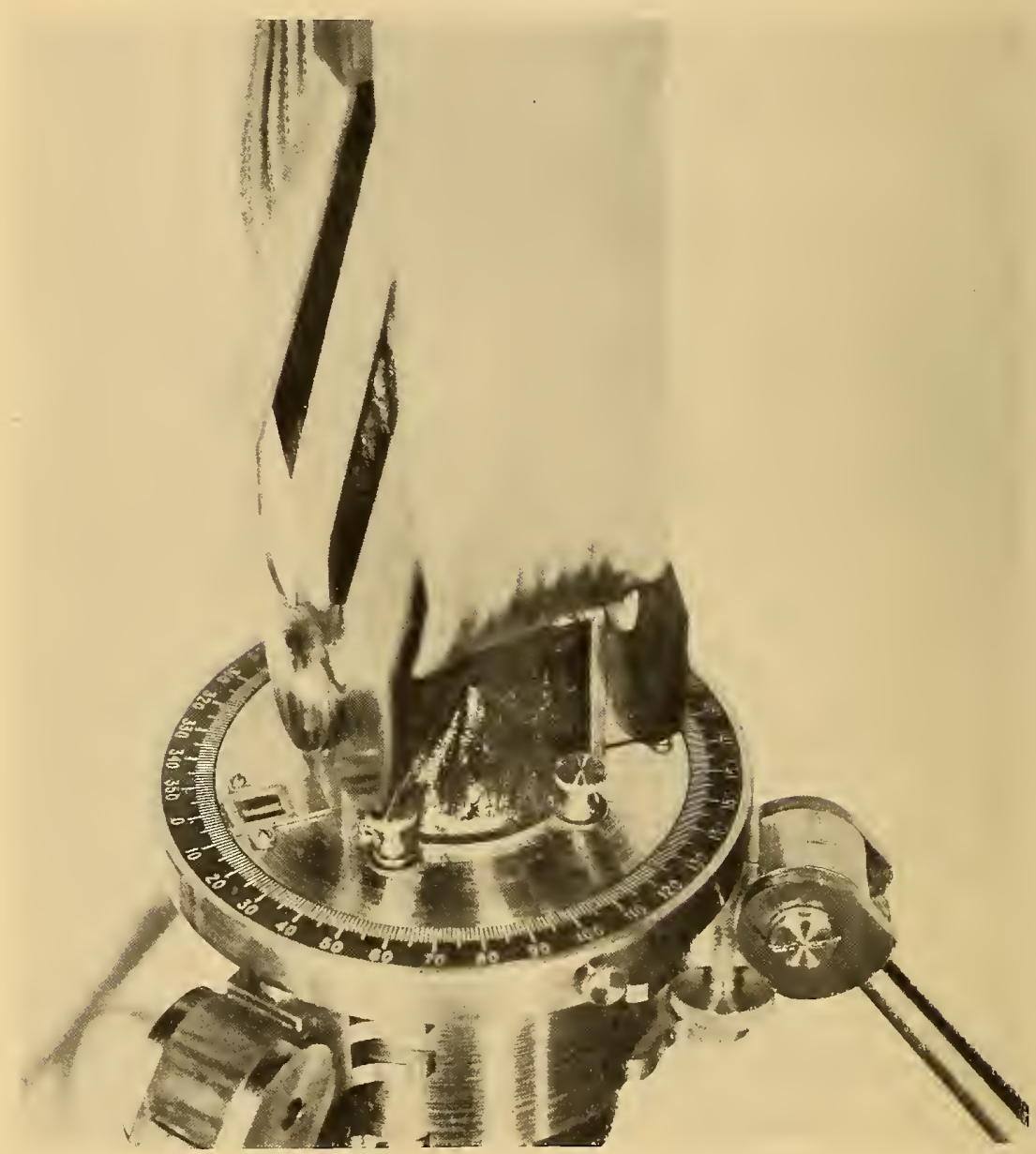

Fig. 25. - Scale and magnetic compass as used on direction funder for ficld use 
systems, it is of interest to study the results obtained in the case where observations of direction were made near the Washington Monument. The Monument is about 555 feet high and has within it an elevator and stairway which form what may be considered as a fairly efficient antenna.

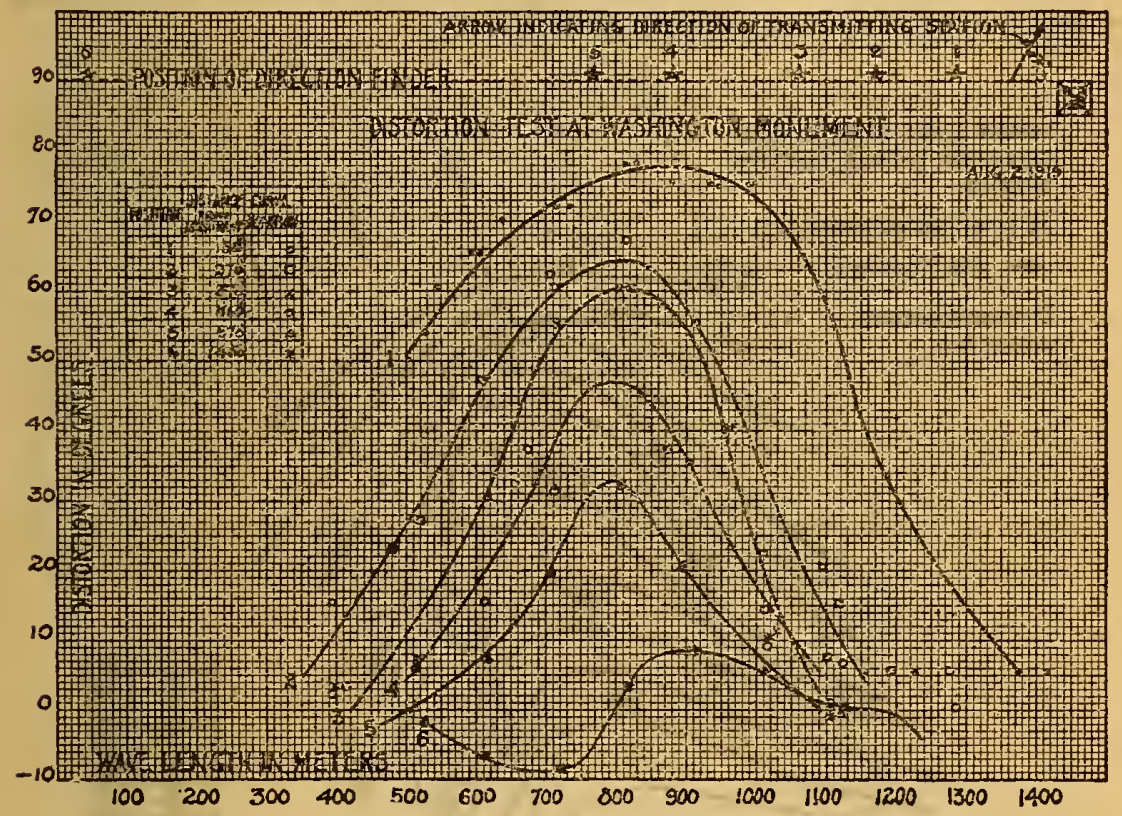

\begin{tabular}{|c|c|c|}
\hline Position & $\begin{array}{l}\text { Distance } \\
\text { from } \\
\text { monu- } \\
\text { ment }\end{array}$ & $\begin{array}{c}\text { Curve } \\
\text { notation }\end{array}$ \\
\hline$x$ & $\begin{array}{c}\text { Feet. } \\
\mathrm{r} 58\end{array}$ & (2) \\
\hline 2 & 270 & $\square$ \\
\hline 3 & 370 & $x$ \\
\hline 4 & 560. & 0 \\
\hline 5 & 670 & $\triangle$ \\
\hline 6 & $x, 400$ & * \\
\hline
\end{tabular}

FIG. 26.-Distortion of radio waves caused by Washington Monument

The results of tests made near the Monument are given in Figs. 26 and 27 , which are self-explanatory.

An interesting fact is brought out by the curves given in Fig. 26 , which show that maximum distortion occurs at a wave length of about 800 meters. This is apparently the natural wave length of the Monument. In other words, the Monument considered as an antenna is in resonance or in tune at this wave length. 
Another interesting case is given in Fig. 28 which shows the distorting effects of a tuned antenna upon the incoming wave as observed at various distances from the lead-in wire of the antenna, indicated by positions $I, 2,3$, and 4 in the figure. The dimensions of the antenna were small as compared with the wave length used in this test, and when the antenna was out of tune no distorting effects were observed even at position I.

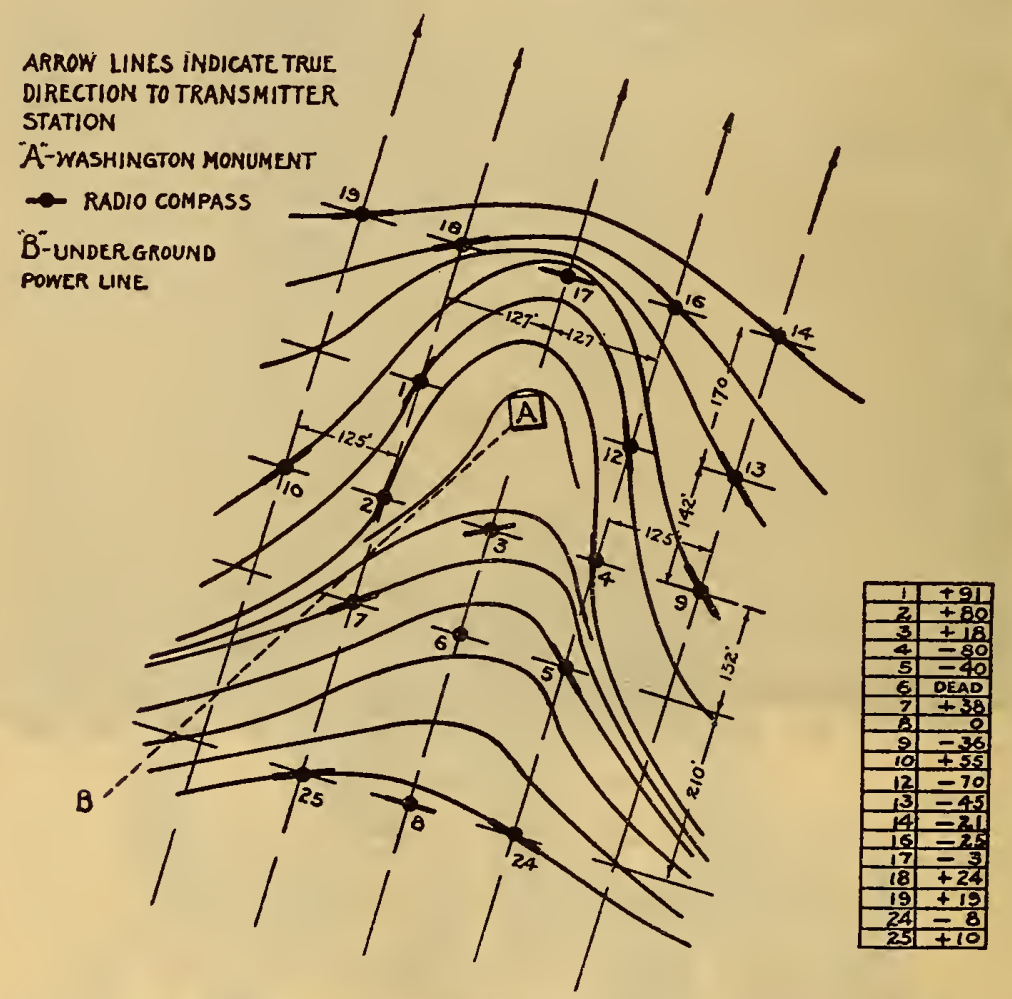

FIG. 27.-Wave distortion at 625 meters caused by Washington Monument

Although the experiments briefly described above were conducted under more or less exaggerated conditions, they serve nevertheless to show that great care must be taken in locating direction-finding stations on land and that in cases where distorting structures or systems can not be avoided a calibration of the direction finder must be made in order that the proper corrections may be applied to the observations taken under given conditions. This matter of calibration will be discussed in greater detail in the following section in which the use of the direction finder on shipboard is described. 


\section{PRACTICAL APPLICATION TO NAVIGATION}

Although the coil receiving system and direction finder have been effectively used for many practical purposes, particularly during the war, its application to navigation is perhaps the most

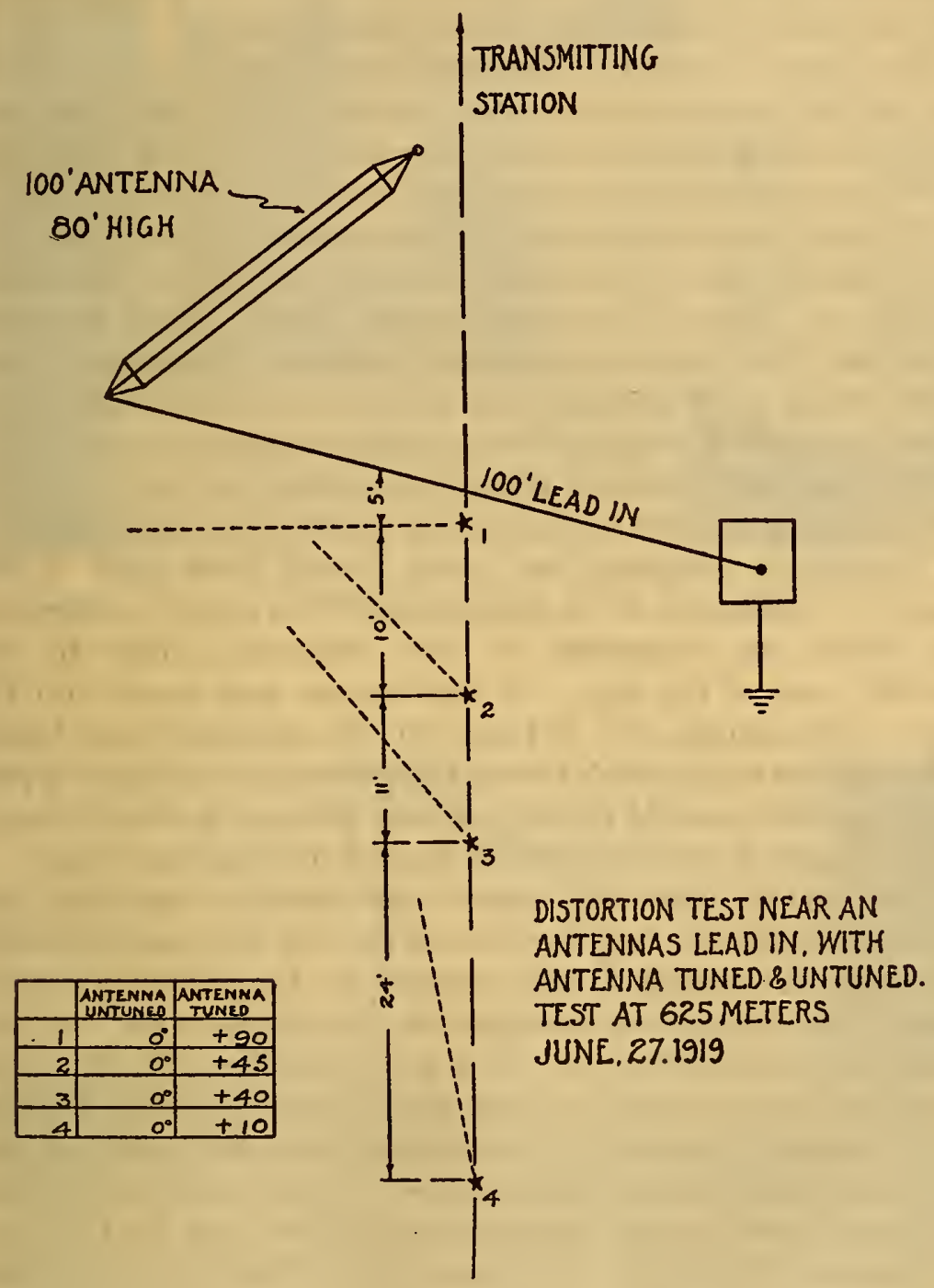

Fig. 28.-Effect of tuned antenna on the indications of a direction finder near the antenna lead-in

important, and it was originally for this purpose that its development was undertaken by the Bureau of Standards.

The first practical tests of the radio fog-signaling and radio direction-finding system were begun in 1916 when the Navesink 
light station at Atlantic Highlands, N. J., was equipped with an automatically operated radio transmitting set. At the same time a direction finder was installed on the lighthouse tender Tulip.

The transmitter installed at Navesink is shown in Fig. 29. A transmitting coil consisting of three turns ro feet square, shown in Fig. 30, was used instead of the customary antenna.

The results obtained in these early tests were very successful, but further progress was stopped because of the war. Immediately after the armistice, however, this work was revived, and in the fall of 1919 more elaborate tests were made in Chesapeake Bay.

For these tests the lighthouse tender Arbutus, shown in Fig. 3I, was equipped with an experimental type of direction finder, shown in Fig. 32. Three lighthouses, namely, Smith Point, Windmill Point, and Wolf Trap, were equipped with radio transmitters, two of the rotary spark type and one of the electron-tube type. The maximum sending range of these signaling stations was only about 20 miles as their radiating power was limited by the size of the antennas, which it will be seen in Fig. 35 was necessarily small.

Considerable attention was given during these tests to the matter of calibration of the direction finder in order to determine the nature and magnitude of wave distortion caused by the metallic mass of the ship. All calibrations were made with the ship's radio antenna out of tune with the signaling wave length and grounded to the ship's hull so that it became essentially a part of the metallic mass of the ship, which, taken as a whole, had an electrical period far different from that of the signaling wave.

The direction finder was placed approximately amidships and on its center line so that the mass of the ship was approximately symmetrically arranged with respect to the direction finder. Under these conditions calibration or correction curves were obtained as shown in Fig. 33. It is seen, therefore, that the radio direction finder on shipboard requires calibration just as does the ship's magnetic compass. A correction must be applied to the observed radio direction, either added or subtracted and varying in amount from zero to a maximum depending upon the fore-andaft positions of the ship with respect to the direction of approach of the signaling wave.

To illustrate the accuracy with which the position of a ship may be determined by means of the direction finder, there is shown in Fig. 34 an actual case in which radio bearings were taken on the Arbutus from each of the three signaling stations or radio beacons. 
Scientific Papers of the Bureau of Standards, Vol, 17

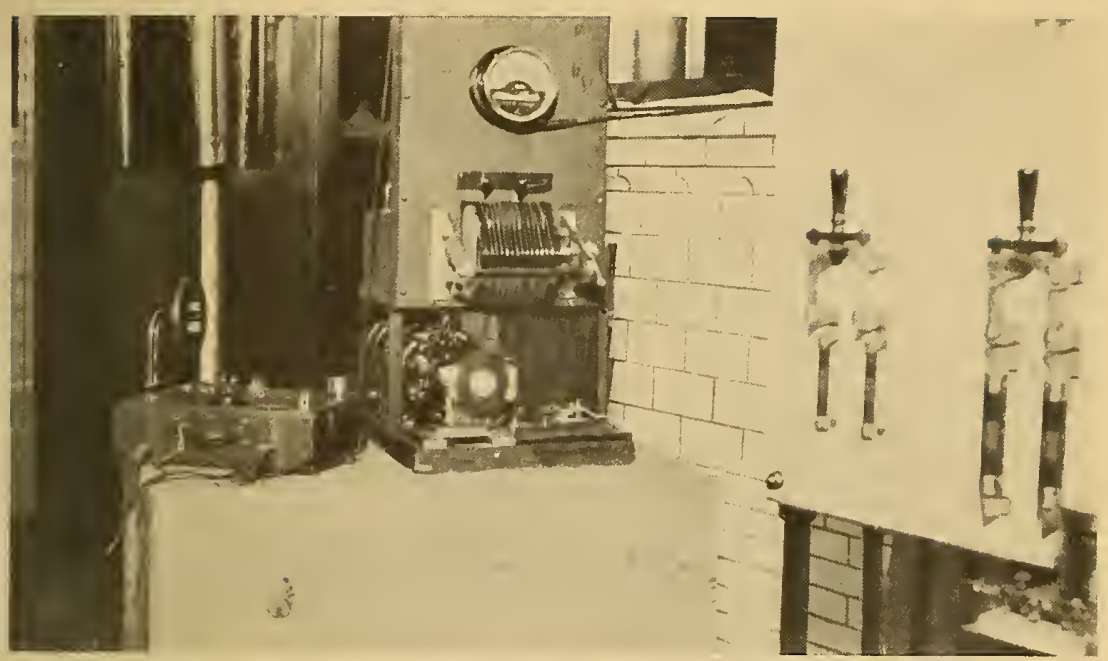

FIG. 29.-Early type of automatic radio beacon transmitter, insialled ai Navesink Lighthouse, Igr6

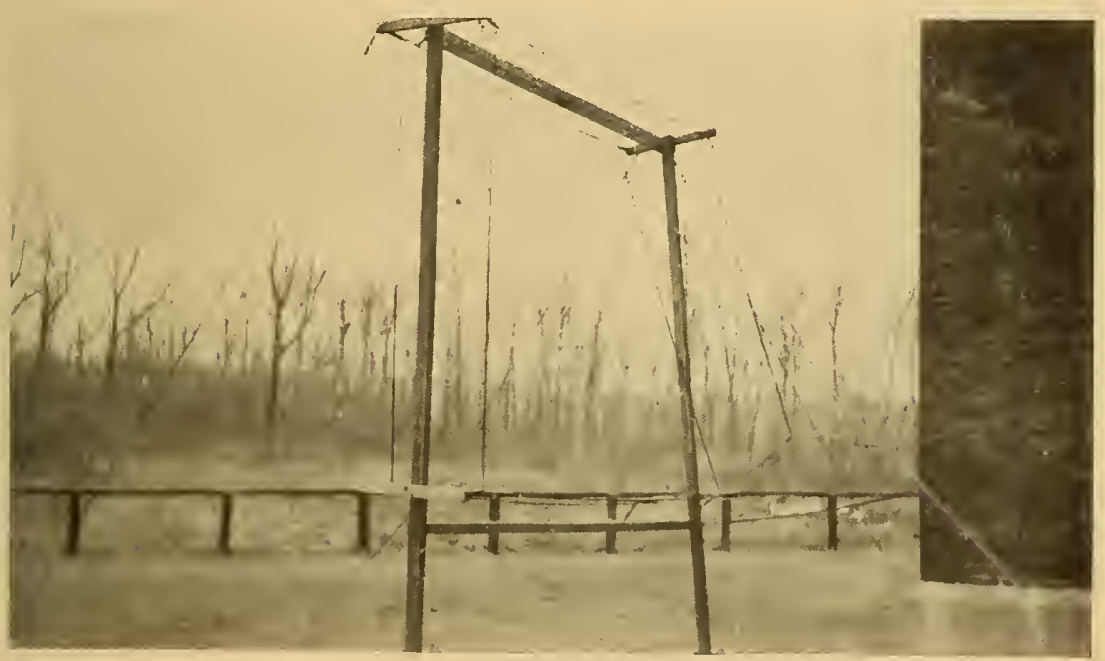

FIG. 30.- Coil aerial transmitter wsed at Navesink Lighthouse, 1916 


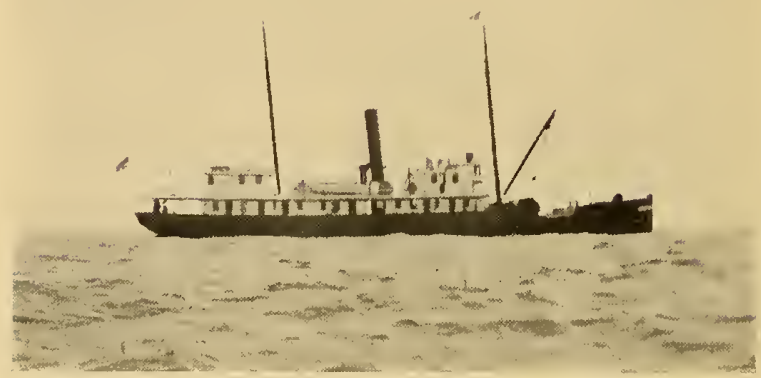

III. 31.-Lighthouse tender "Arbutus," showing experimental type of direction finder just aft of pilol house

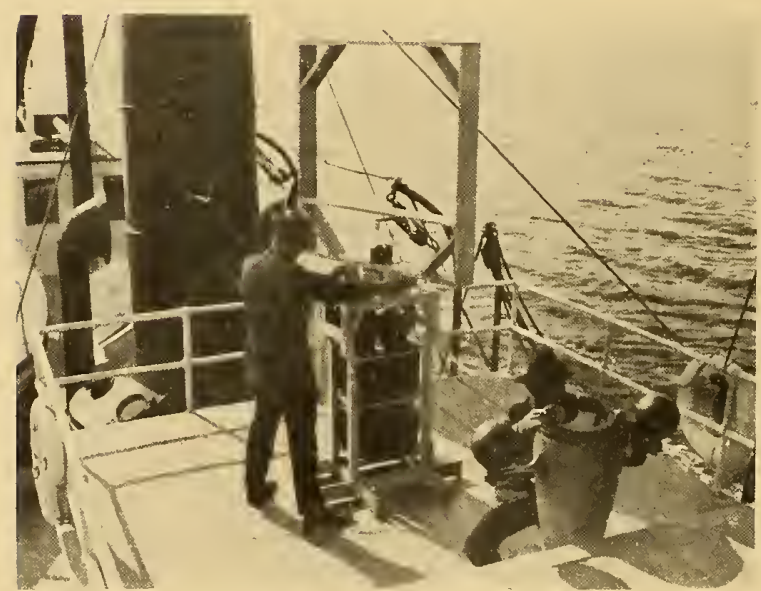

FIG. 32.-Experimental type of direction finder on lighthouse tender "Arbutus" 
The intersection of these bearings drawn on the chart from each of the light stations gives the observed position of the ship. A

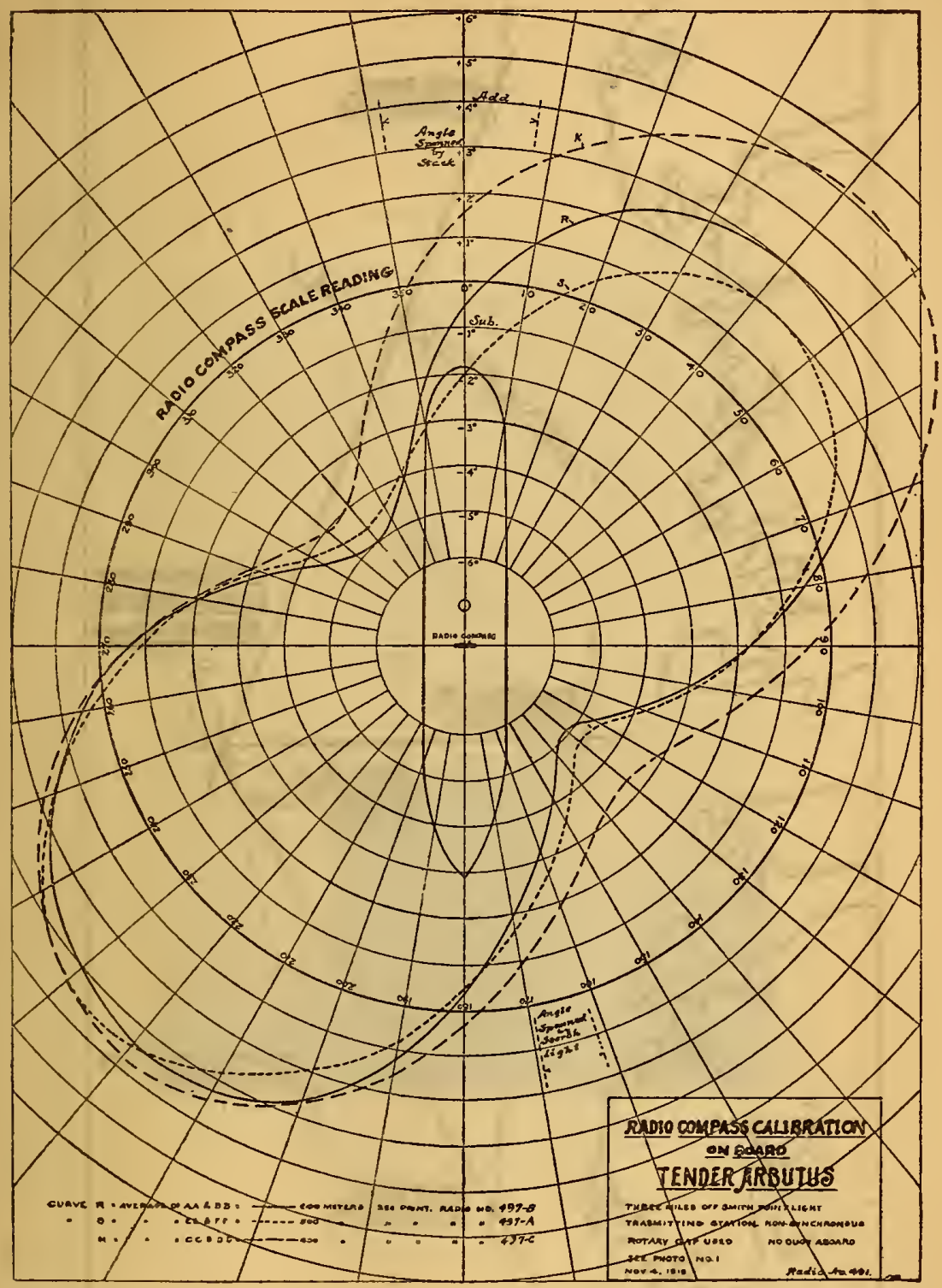

Fig. 33.-Calibration curve for the direction finder as installed on the lighthouse tender "Arbutus"

fourth check bearing taken from the naval radio station at Norfolk is also shown. The actual position of the ship was at buoy io $\mathrm{C}$. 


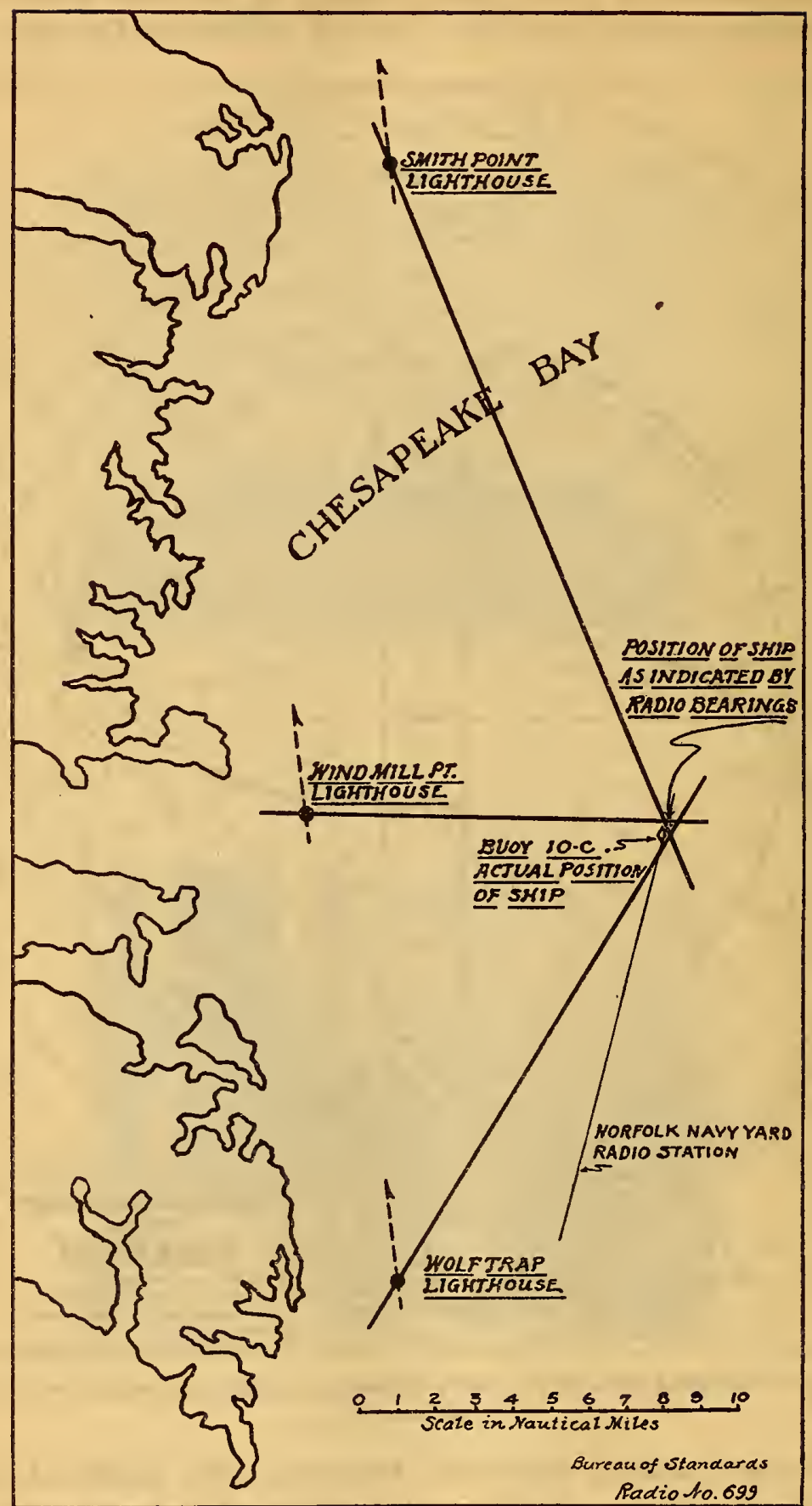

FIG. 34.-Actual case of triangulation from the three Chesapeake Bay radio beacons 


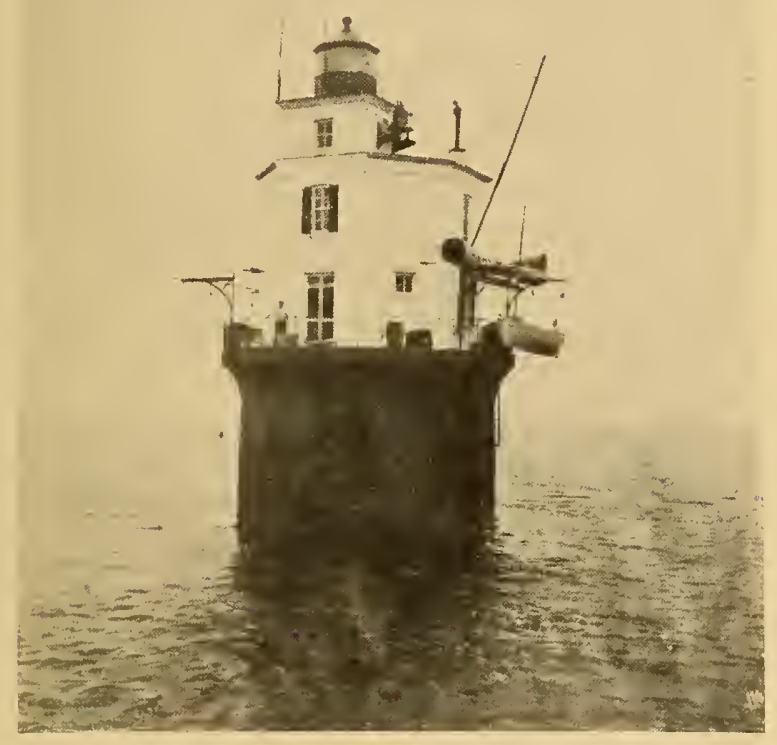

Fig. 35. Smith Point Lighthouse equippal experimentally as a radio bcacon 
The success of the Chesapeake Bay tests has led to the permanent installation of radio fog-signaling equipment on the Fire Island and Ambrose Channel light vessels, and at the Sea Girt light station on the New Jersey coast below Asbury Park. The Sea Girt radio beacon station is shown in Fig. 36 and the signaling apparatus in Fig. 37. The radio transmitter is of the quenchedspark type supplied from a 500-cycle, I-kw generator. The automatic signaling system is shown to the right of the figure and is designed to transmit a characteristic signal consisting of three dots sent out in rapid succession at frequent intervals. The Fire Island and Ambrose Channel light vessels are equipped with similar apparatus, but having different signal characteristics.

Dot-signal characteristics have been adopted because of the ease with which they can be distinguished by the observer who may not be a radio operator. The signal characteristic of the Fire Island light vessel is two dots sent out in rapid succession and that of the Ambrose Channel light vessel, single dots. In each case the signaling station transmits for a given interval of time and then remains silent for a given interval of time, these time intervals being different for each station. The wave length used is 1000 meters which has been tentatively chosen by international agreement. It is possible, however, that it will be found necessary in cases where the three radio beacons are comparatively close together, to use wave lengths slightly different from each other, as, for example, 950, 1000, and ro5o meters, in order to overcome the difficulty of interference, although in general this difficulty is satisfactorily solved by the proper choice of the signaling and silent periods for each station. The signaling apparatus as installed on the Fire Island and Ambrose Channel light vessels is entirely automatic in its operation and is designed to be operated by the personnel of the station with only occasional inspection by a radio engineer attached to the office of the superintendent of the lighthouse district.

As an example of a direction-finder equipment for shipboard installation, that of the lighthouse tender Tulip is of interest and will be described in connection with the results obtained in a series of tests conducted during the summer and fall of 1920 .

The direction-finder coil is shown in Fig. 38 and consists of $\mathrm{II}$ turns of insulated wire wound on a rigid skeleton frame 4 feet square. The coil is attached to a shaft which extends into the pilot house through suitable bearings and which is supported on ball bearings in order to permit ease and uniformity of rotation. 
Another view of the direction-finder coil is shown in Fig. 39 where it is seen directly over the pilot house and on the center line of the ship. The interior view of the pilothouse, Fig. 38 , illustrates the method of attaching the direction finder to the binnacle carrying the magnetic compass. By means of this arrangement radio bearings are observed in a simple and direct manner. The exterior coil is rotated from within the pilot house by means of a handwheel, and the bearing of the signaling station is read directly on the magnetic compass card. In Fig. 40 the captain of the Tulip is seen taking the radio bearing of the Fire Island light vessel.

A calibration or correction curve for the Tulip direction finder was obtained by taking simultaneous visual and radio bearings on one of the light vessels while the Tulip made a circular course at a distance of a few miles from the light vessel. This correction curve is shown in Fig. $4 \mathbf{I}$, and it will be noted that it approaches very nearly a sine curve. It will be noted further that maximum deviation from true direction occurs when the direction of approach of the signaling wave is approximately at $45^{\circ}$ with the ship's center line; that is, when the mass of the ship assumes an unsymmetrical relation with respect to the approaching wave front. In the fore-and-aft direction and directly abeam the deviation is zero or nearly so because of the more or less symmetrical arrangement of the ship's mass with respect to the direction of approach of the wave front. This, of course, holds true only when the direction finder is located approximately amidships.

Once the correction curve has been obtained for the particular wave length assigned to the radio fog-signaling stations or radio beacons, a correction scale may be made in accordance with the curve, which, if attached to the binnacle as shown in Fig. 42, provides convenient means for reading the bearing and correction simultaneously.

The electrical circuit of the direction finder is given in Fig. 43. The variable condenser $C_{0}$ together with the coil $L_{0}$ form the main receiving circuit which is tuned to the signaling wave length. Connected across the condenser $C_{0}$, either directly or through a potential transformer $P$, is the vacuum tube amplifying and detecting apparatus $D$. This consists of a three-stage radiofrequency amplifier, a detector, and a two-stage audio-frequency amplifier made up as a unit with a minimum number of operating adjustments. 
Scientific Papers of the Bureau of Standards, Vol, 17

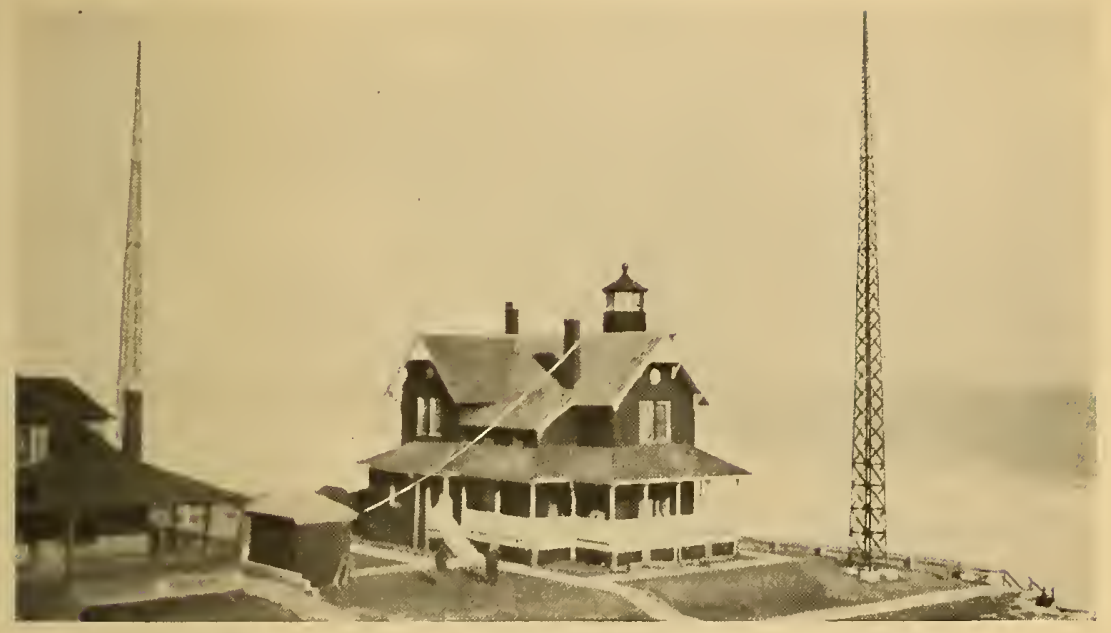

FIG. 36-The Sea Girt Lighllouse equipped as a radio beacon

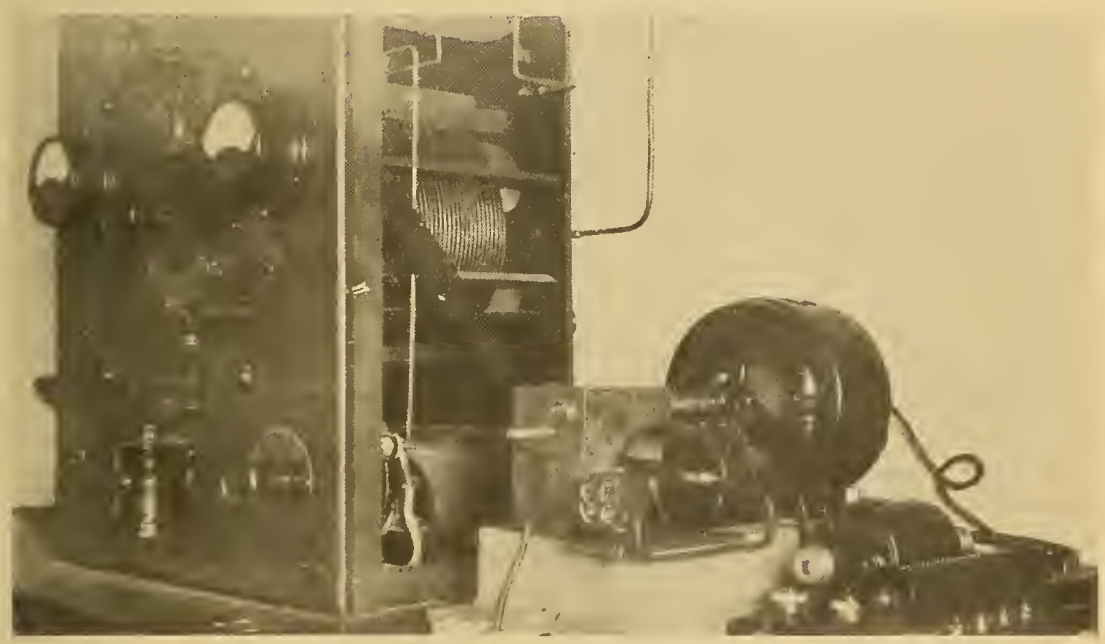

Fìg. 37.- Radio baton transmitter with aulomatic signaling key for giving the beacon churacteristic 


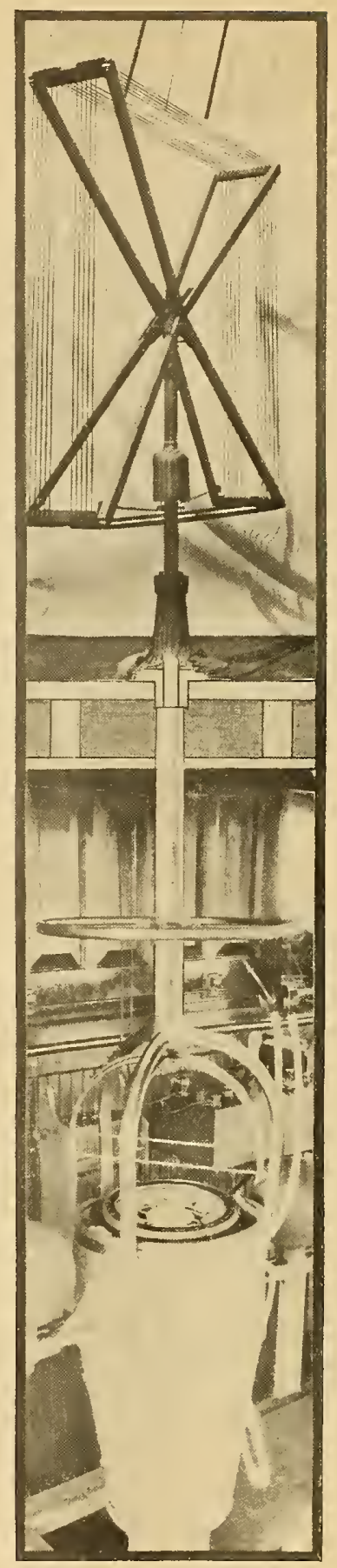

FIG. 38.-Magnetic compass with dircciion finder attachment for reading the radio bearing directly on the magnetic compass 
Scientific Papers of the Bureau of Standards, Vol. 17

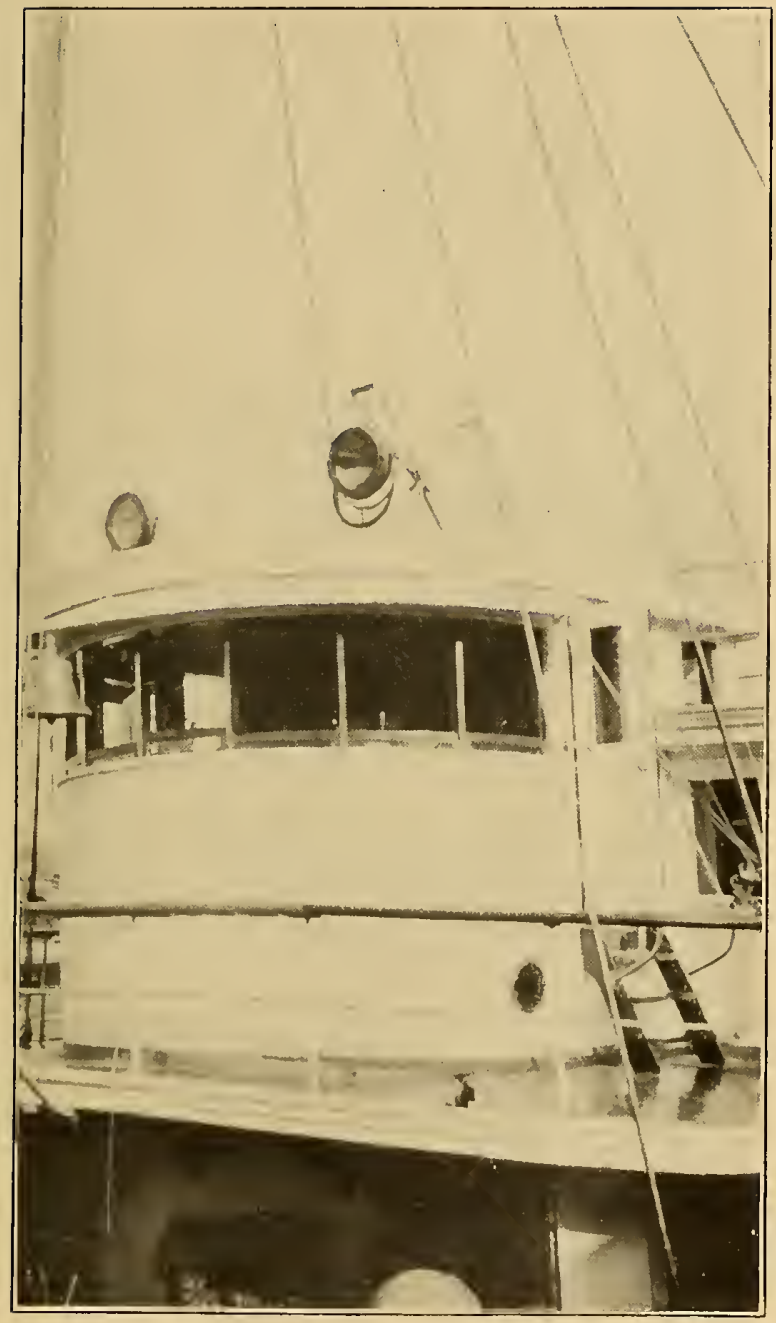

Fig. 39.-Pilot house of lighthouse tenler "Tulip," shouing location of dircction finder 
Scientific Papers of the Bureau of Standards, Vol. 17

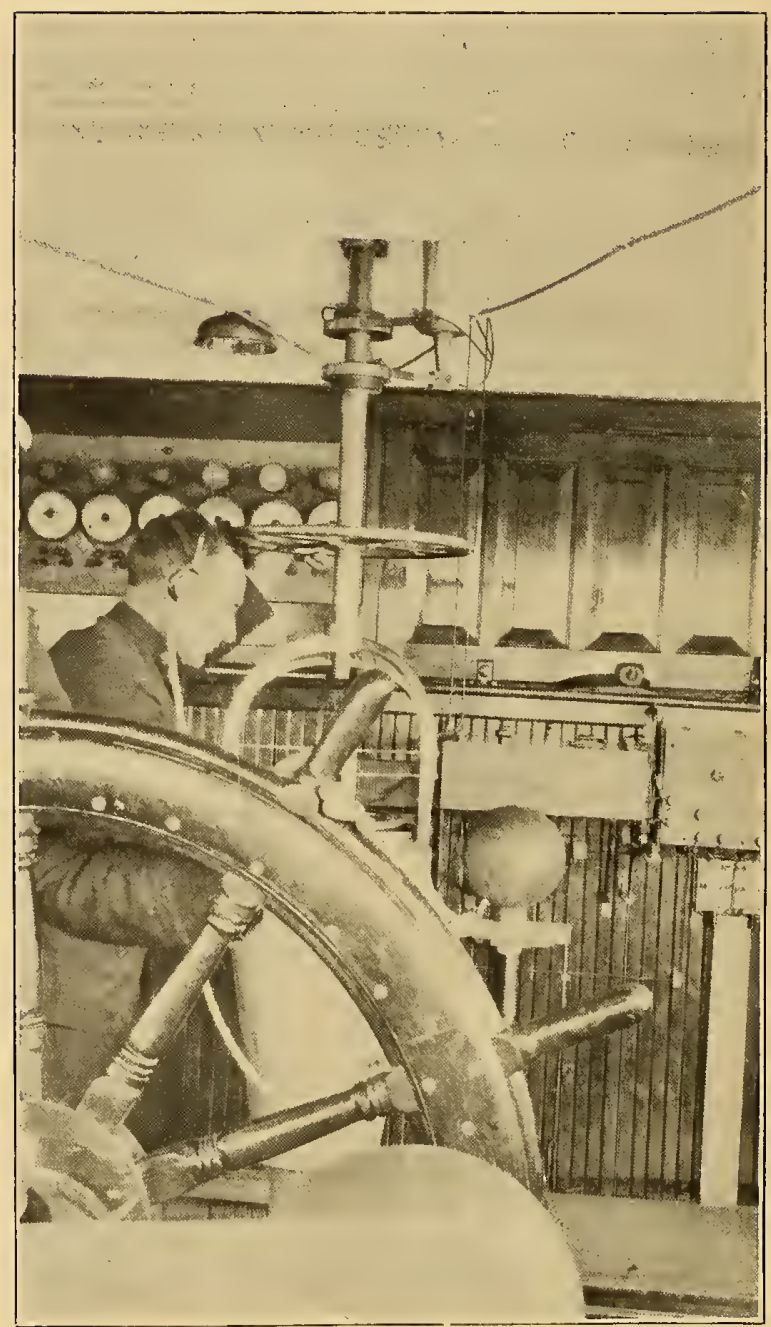

FIG. 40.-The captain of the lighthouse tender "Tulip" operating the radio direction finder 

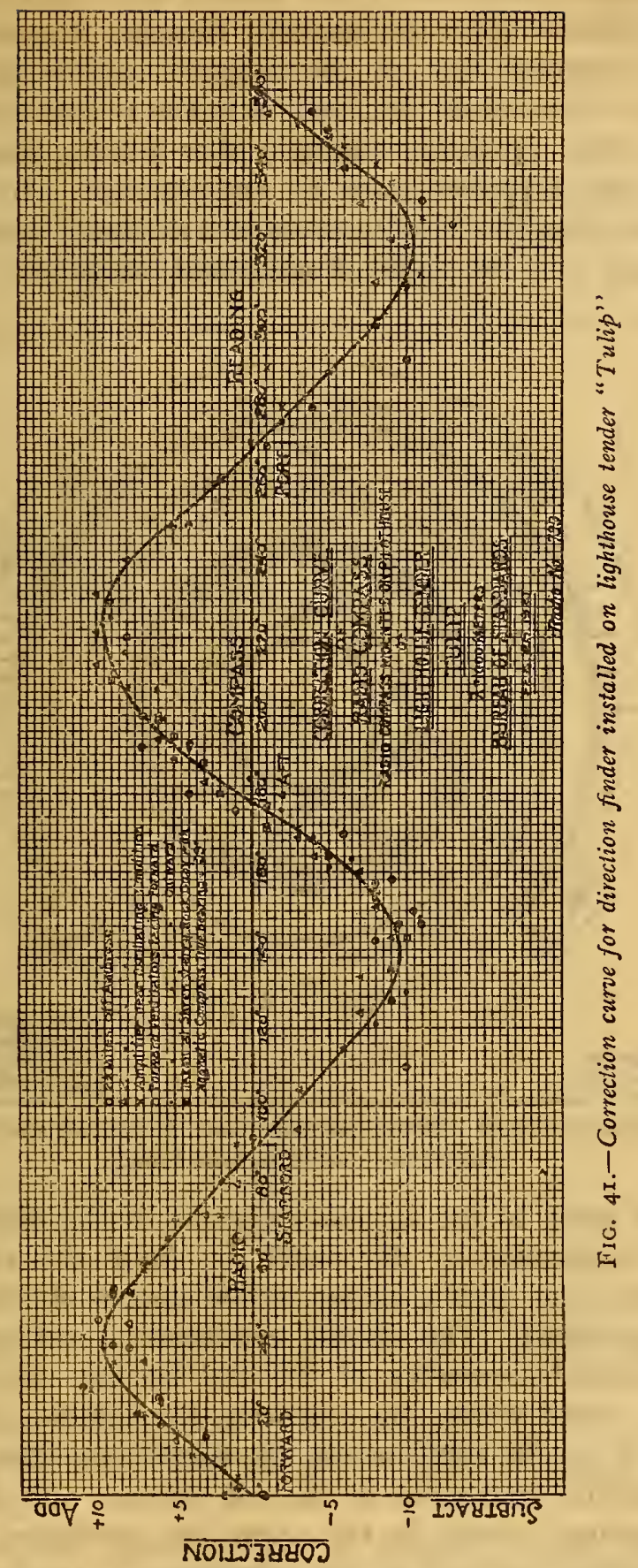

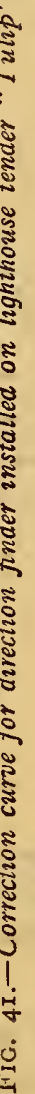


The telephone receivers $T$ are located in a fixed position at a sufficient distance from the magnetic compass to avoid any effect upon the compass due to the magnets within the telephone receivers. A brass tube is attached to the telephone receivers as shown in Fig. 44 with flexible rubber tubing completing the circuit to the earpieces worn by the observer. By the proper choice of the length of the brass tube a desirable quality is given to the signal tone by virtue of acoustical resonance.

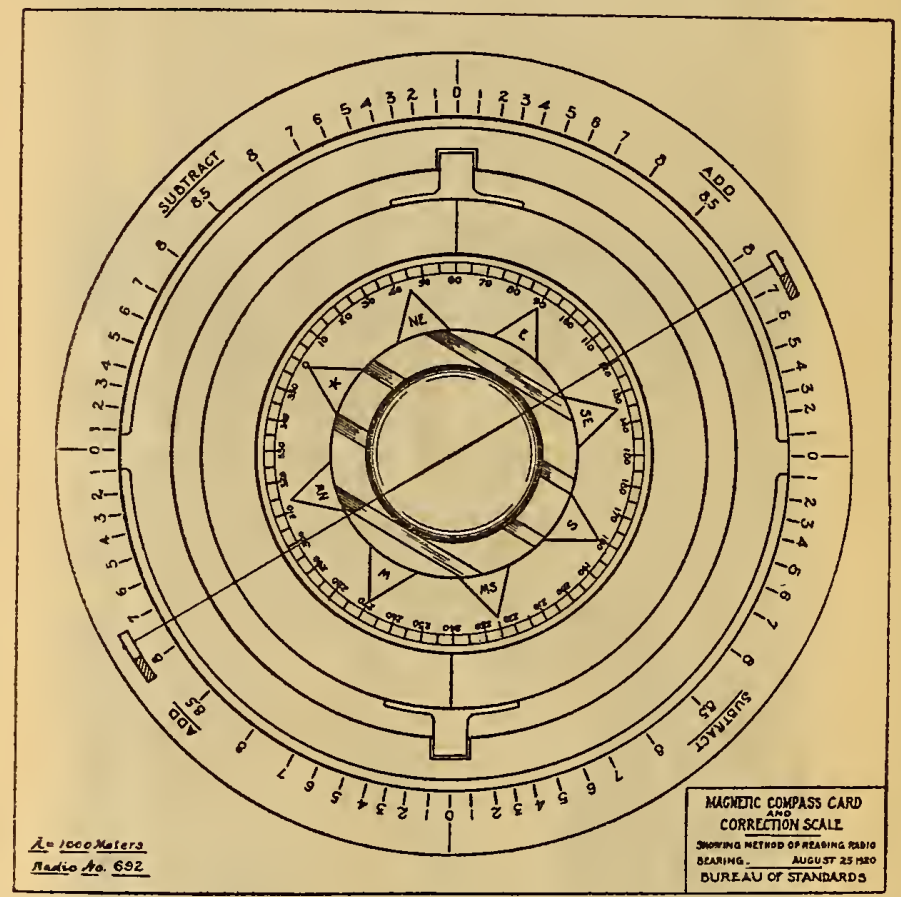

FIG. 42.-Magnetic compass card and correction scale showing the direct-reading method of obtaining a corrected radio bearing

We now come to the auxiliary circuits of the direction finder which are controlled by the switch $S$. With this switch closed to the right, the middle plates of the double condenser $C_{3}$ are directly grounded. The double condenser is utilized to bring about electrical symmetry of the coil system with respect to earth. In other words, by adjusting the middle plates of the condenser $C_{3}$ to the right or left, the earth connection is brought to the electrical mid-point of the coil system, and the parasitic effects described earlier in the paper are eliminated, that is to say, the signal received in the telephones $T$ results only from the energy directly received in the coil $L_{0}$. 
With the switcil $S$ closed to the left, a small condenser $C_{2}$ is connected across half of the double condenser $C_{3}$ and the inductance $L_{1}$ and tuning condenser $C_{1}$ are inserted in the ground lead. Under these conditions, the coil system is no longer electrically symmetrical with respect to earth, and received energy enters the coil circuit $L_{0} C_{0}$ indirectly through the tuned

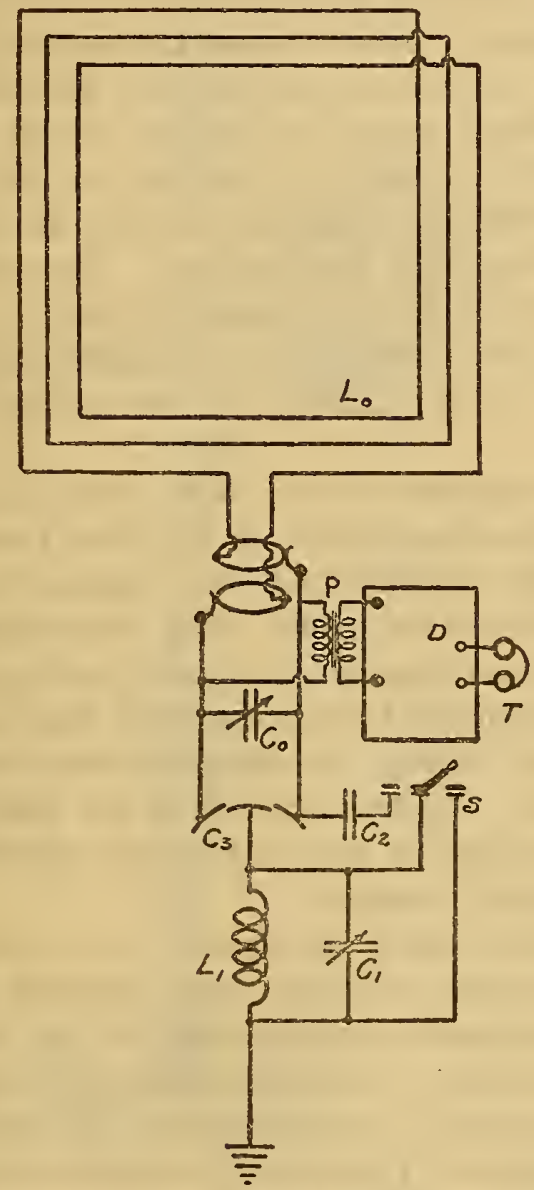

Fig. 43.-The direction finder circuit

ground circuit of which the capacity of the complete coil system to earth forms a part.

By the proper adjustment of the capacity $C_{2}$ and the circuit $L_{1} C_{1}$, a complete unidirectional effect can be obtained as previously described.

In the practical operation of the direction finder, all tuning adjustments remain set for the I000-meter wave length of the $69405-22-3$ 
signaling stations. Switch $S$ is closed to the right when observing the line of direction of a given signaling station and to the left when it is desired to determine the sense of direction. In other words, to determine the line of direction of a station, the coil system which is directly grounded at its electrical mid-point by throwing switch $S$ to the right is rotated to the position of critical silence, at which time the plane of the coil is normal to the direction of approach of the signaling wave. To determine the sense of direction of the station, switch $S$ is closed to the left and the coil rotated to the position of maximum signal intensity at which time the plane of the coil is in the direction of approach of the signaling wave and pointing toward the signaling station as indicated by an index pointer provided for that purpose. The complete direction finder system is shown with details in Fig. 45.

The results of actual tests conducted under most practical conditions are shown by the charts, Figs. 46 and 47 , which are selfexplanatory.

The 45 -mile run shown in Fig. 46 was made on radio bearings taken from the signaling station on the Fire Island light vessel. During this run the direction finder was operated and all bearings taken by the captain of the tender Tulip, who had had no previous experience in the operation of any kind of radio apparatus.

In Fig. 47 the estimated positions of the Tulip at quarter-hour intervals are given during the south-by-west course taken from Jones Inlet buoys. The true position of the ship, as determined by radio bearings taken on two of the three signaling stations, is also shown in several instances.

The accuracy with which the position of a ship may be determined by triangulation, resulting from bearings taken by radio on two or more signaling stations, depends, of course, upon the sense, whether positive or negative, and order of magnitude of the possible error made in observing the radio bearing of each of the signaling stations. Theoretical triangulations are shown in Fig. 48, in which an exaggerated error of plus or minus 2 degrees is assumed in each case. Any set of three observations or bearings will locate the ship within a triangular area, but the true position of the ship may be entirely outside of this area but within a starshaped area formed as shown in Fig. 48, the details of which are shown in Fig. 49. 
Scientific Papers of the Bureau of Standards, Vol. 17

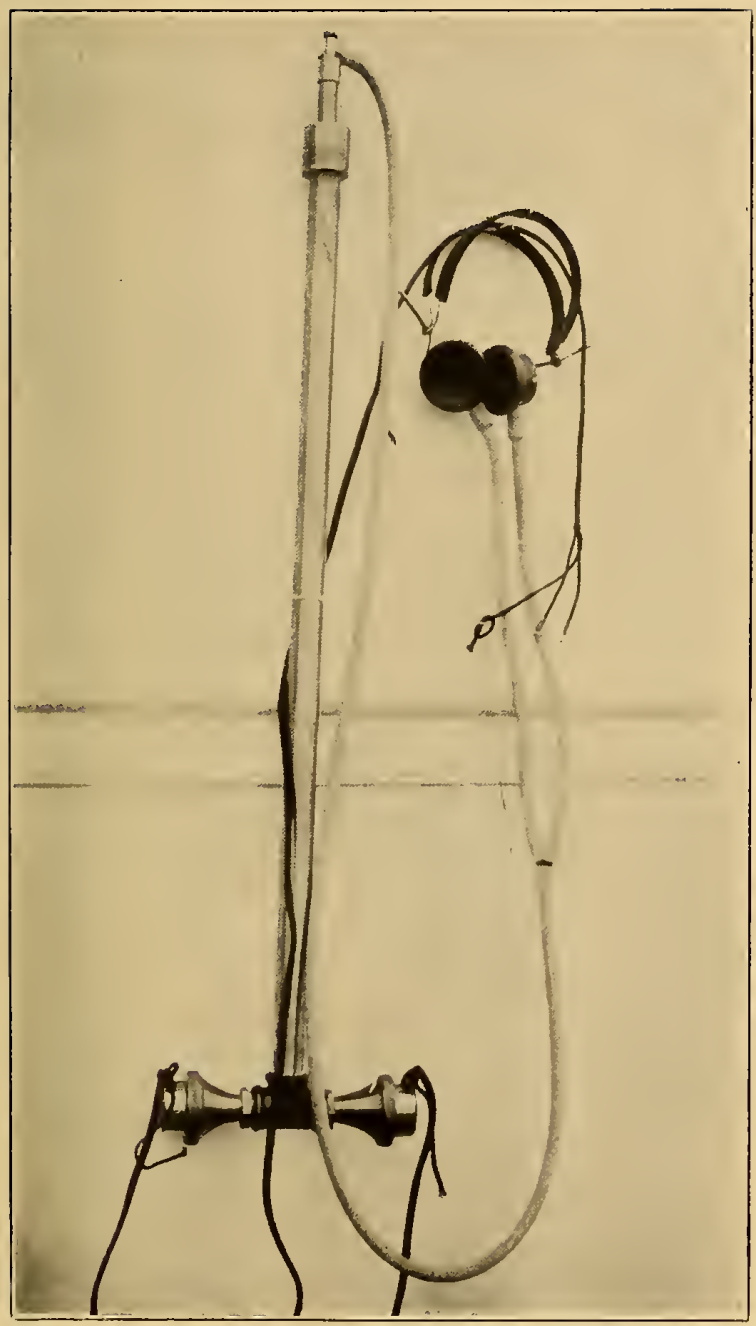

FIG. 44.-Method of keeping telephone veceivers at a fixed distance from the magnetic compass 


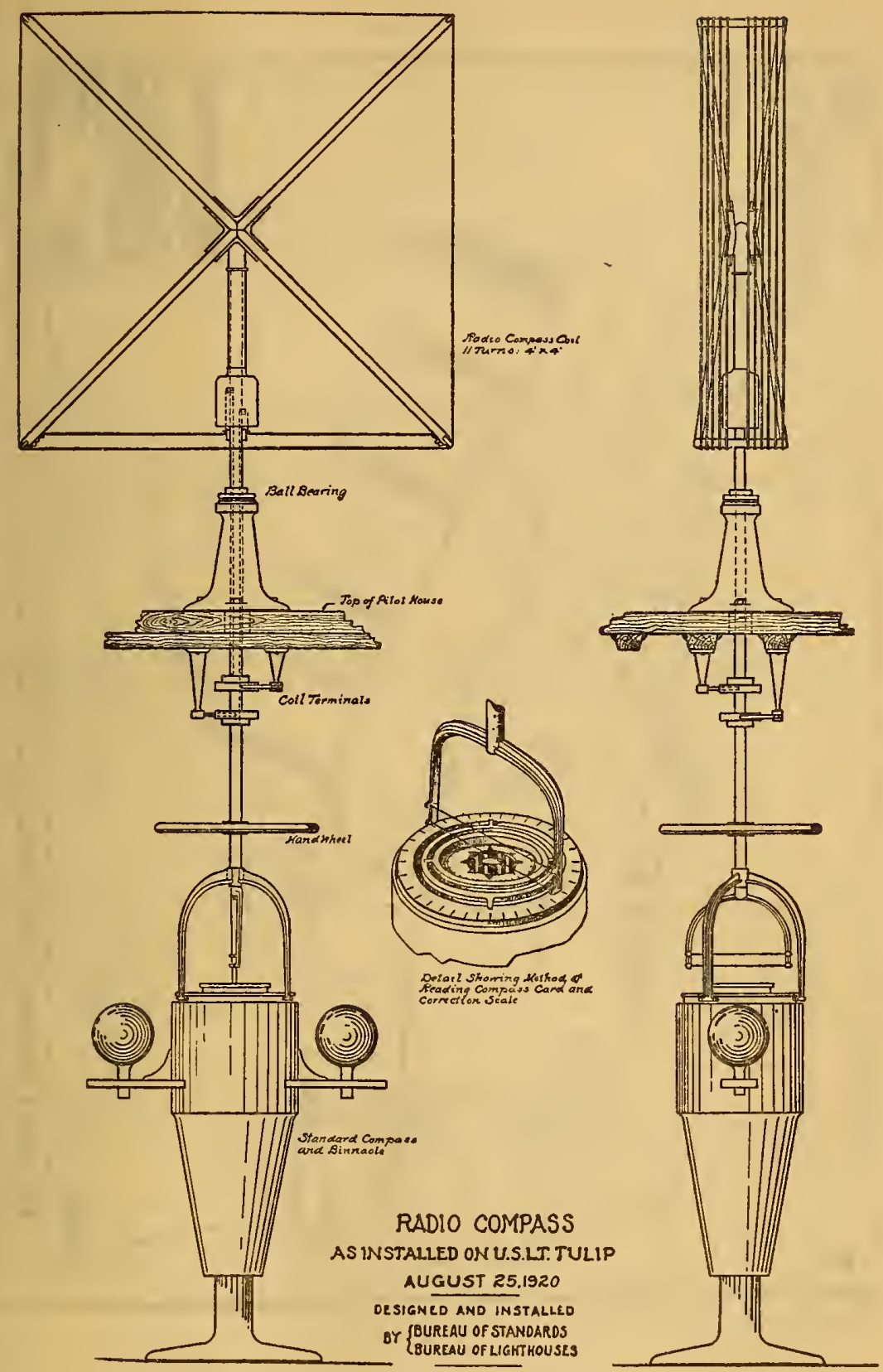

FIG. 45.-Radio direction finder as developed by Bureau of Standards and Bureau of Lighthouses 


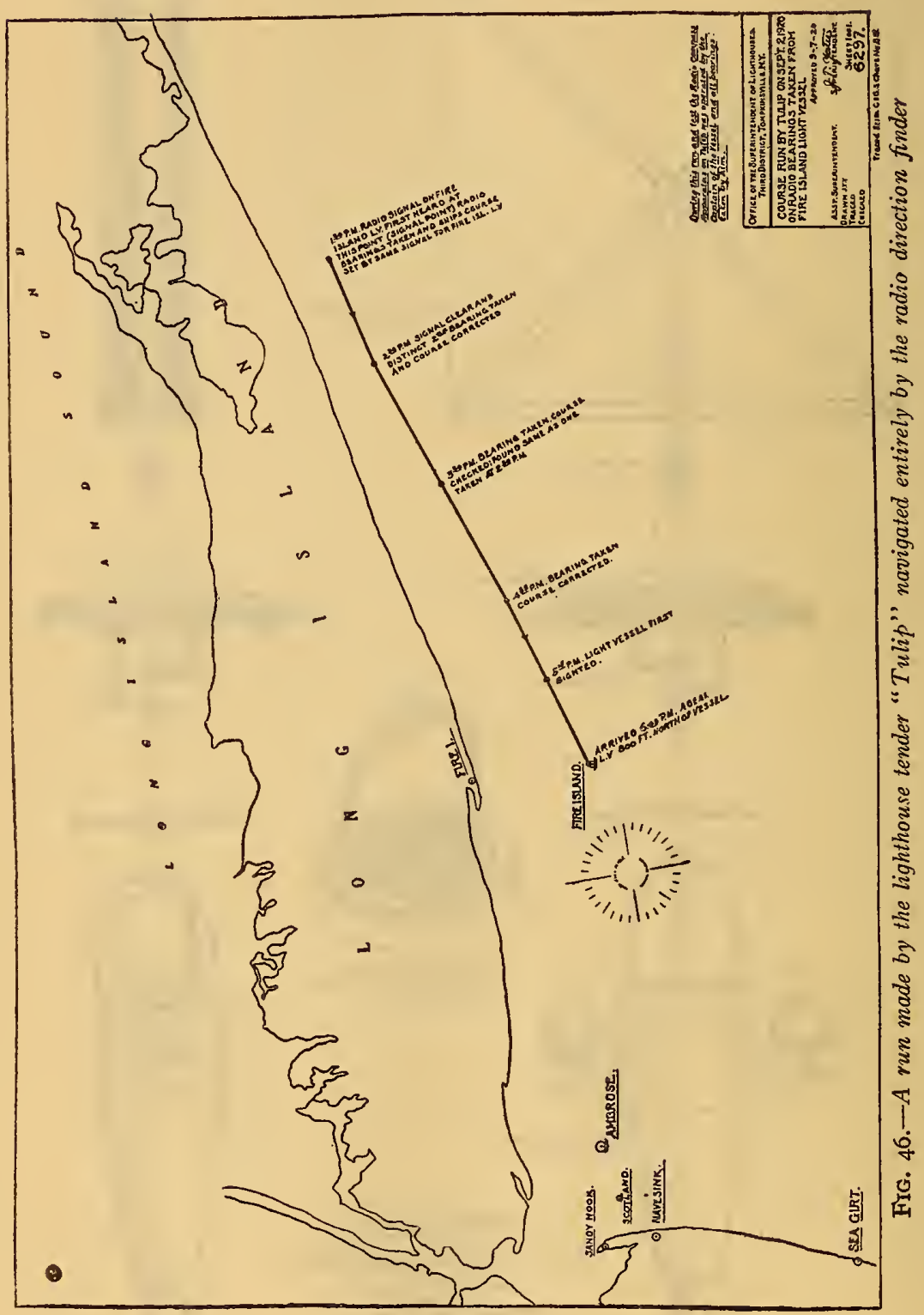




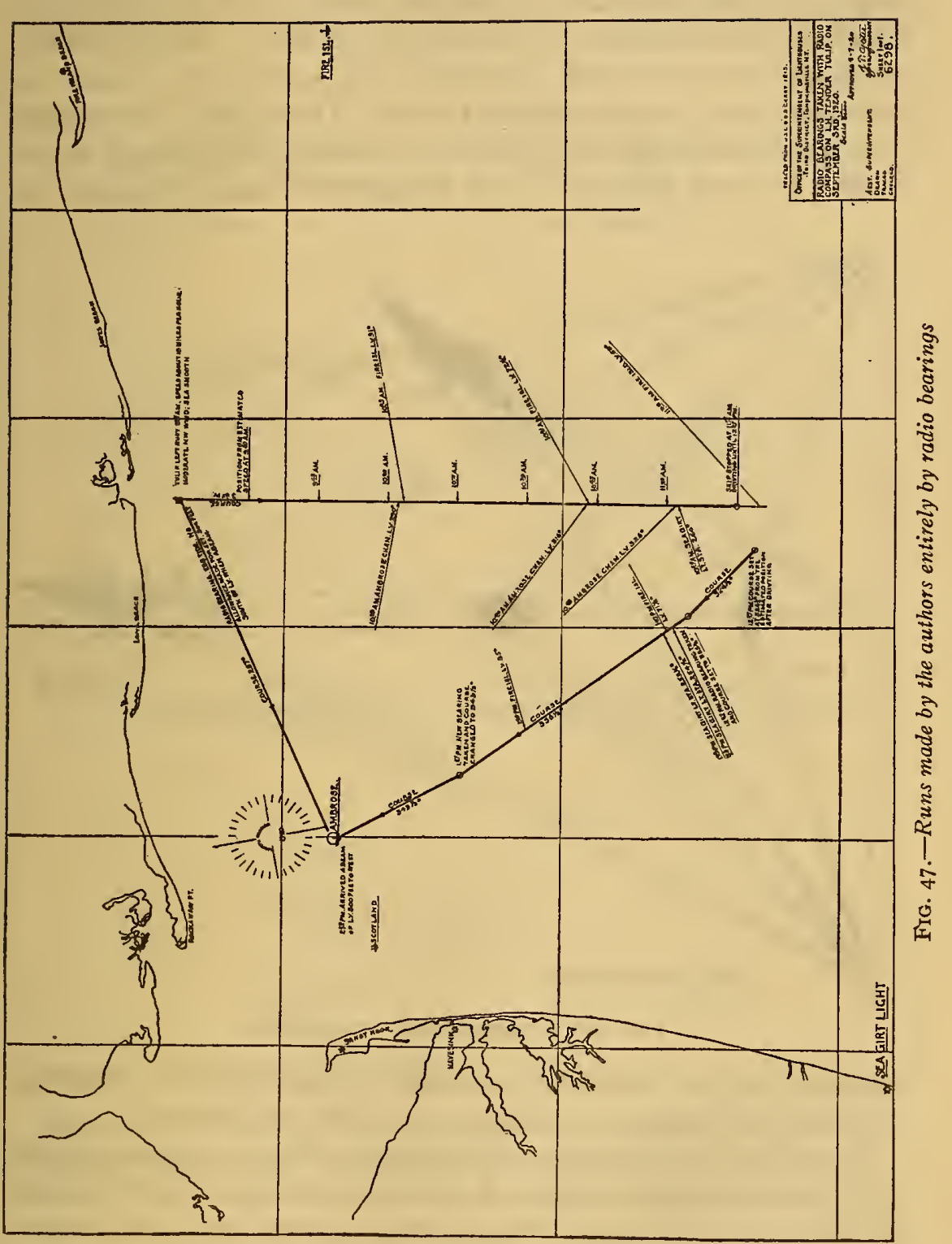




\section{CONCLUSION}

In conclusion it may be definitely stated that the radio direction finder, or radio compass, as herein described, is an extremely effective aid to navigation, particularly in fog or thick weather. If properly constructed, installed, and calibrated, it can be depended upon to give reliable results. The device is essentially a nautical instrument and should be installed on shipboard, where it may be used directly by the navigator in taking bearings on

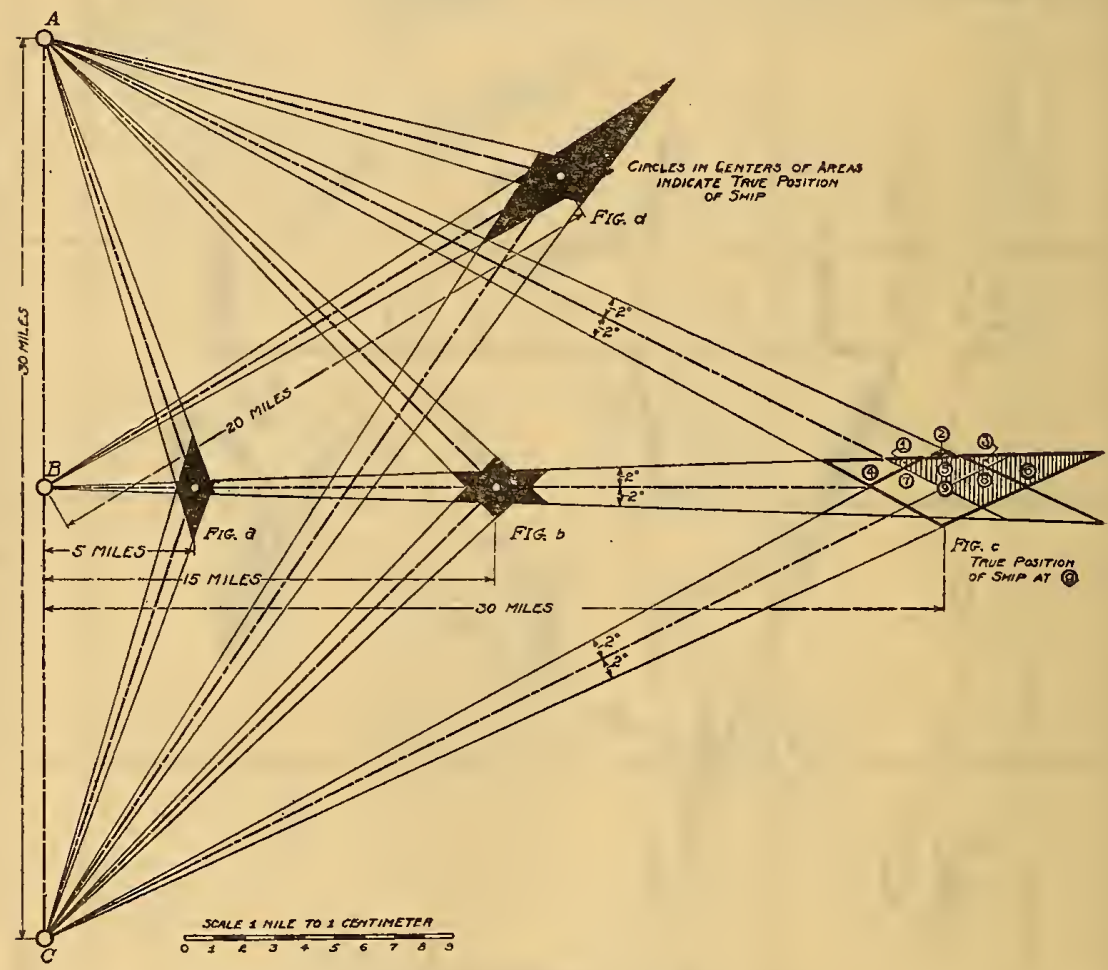

FIG. 48.-Accuracy of radio triangulation

signaling stations established on shore or on light vessels. Bearings may thus be taken at any time and as often as desired.

The reverse method of locating direction-finder stations on shore and requiring the navigator of a ship to make a request for his bearing or position from time to time, as conditions may permit, is fundamentally wrong. Delays and errors are inherent, and even under the most favorable conditions the time consumed in making a request for bearings, taking bearings, and getting the information into the navigator's hands, is too great. 
The maintenance of a 24 -hour service at the required number of shore direction-finder stations requires a large operating personnel, continually on watch but only occasionally called upon for service. This places great responsibility and expense upon the Government.
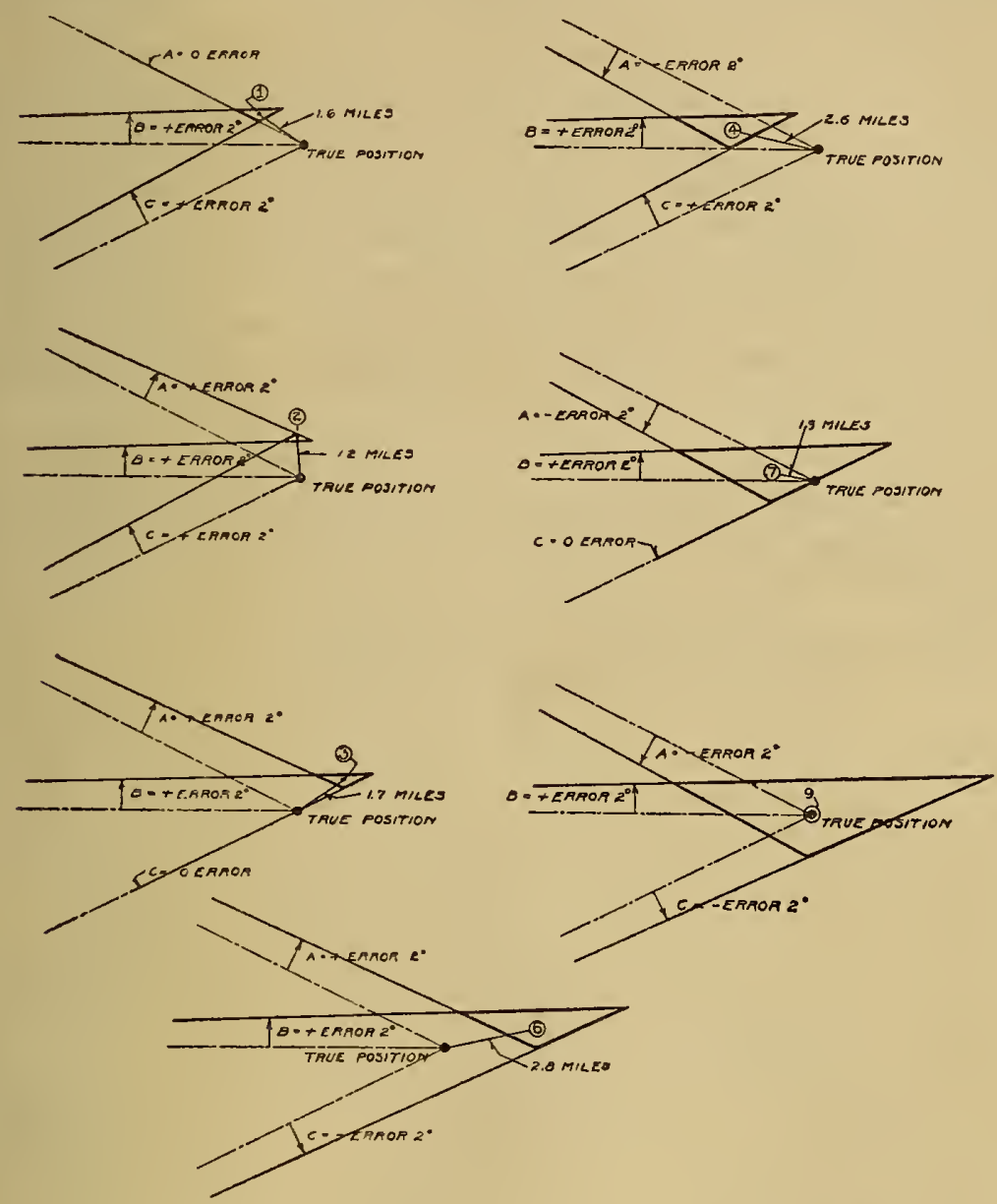

FIG. 49.-Accuracy of radio triangulation, showing true and observed position

Signaling stations, whose locations are accurately shown on mariners' charts, may be established at lighthouses and on light vessels at very little expense. Such stations would thus become a part of an already well-established service whose function is strictly that of maintaining aids to navigation. No additional personnel is required since the operation and maintenance of the radio-signaling apparatus would be the duty of the light keeper. 
The cost of the radio direction-finder equipment for shipboard installation is so small as compared with the benefits which may be derived therefrom, perhaps in a single instance, where life, property, or even time may be saved, that it can not enter into consideration.

The utility of the direction finder on shipboard goes further than that of taking bearings on known stations on or near shore. Other ships at sea, perhaps in distress or in fog, can be located and their course determined. As a matter of safety, every ship at sea in fog should send out radio fog signals at frequent intervals, effective over a distance of at least ro miles. This would enable another ship within range equipped with a radio direction finder to determine the direction and course of the signaling ship and thereby proceed with safety and without delay.

The work of the Bureau of Standards herein described has been conducted with the assistance and close cooperation of the Bureau of Lighthouses and particularly of the lighthouse depot at Tompkinsville, N. Y.

WASHINGTON, July 9, I921. 